Check for updates

Cite this: RSC Adv., 2020, 10, 35658

Received 25th August 2020

Accepted 17th September 2020

DOI: 10.1039/dOra07301f

rsc.li/rsc-advances

\section{Synthesis and biological activities of novel trifluoromethylpyridine amide derivatives containing sulfur moieties $\uparrow$}

\begin{abstract}
S. X. Guo, F. He, A. L. Dai, R. F. Zhang, S. H. Chen and J. Wu (DD*
A series of trifluoromethylpyridine amide derivatives containing sulfur moieties (thioether, sulfone and sulfoxide) was designed and synthesized. Their antibacterial activities against Xanthomonas oryzae pv. oryzae (XoO), Ralstonia solanacearum ( $R$. solanacearum) and insecticidal activities against $P$. xylostella were evaluated. Notably, the half-maximal effective concentration $\left(E_{50}\right)$ value of sulfone-containing compound $\mathrm{F} 10$ is $83 \mathrm{mg} \mathrm{L}^{-1}$ against $\mathrm{XoO}$, which is better than that of commercial thiodiazole copper (97 $\mathrm{mg} \mathrm{L}^{-1}$ ) and bismerthiazol (112 $\mathrm{mg} \mathrm{L}^{-1}$ ). Thioether-containing compounds E1, E3, E5, E6, E10, E11 and E13 showed much higher activities against $R$. solanacearum with the $E_{50}$ value from 40 to $78 \mathrm{mg} \mathrm{L}{ }^{-1}$, which are much lower than that of thiodiazole copper $\left(87 \mathrm{mg} \mathrm{L}^{-1}\right)$ and bismerthiazol (124 $\mathrm{mg} \mathrm{L}^{-1}$ ). Generally, most of the sulfone-containing compounds and sulfoxide-containing compounds showed higher activities against XoO than that of the corresponding thioether-containing compound, but most of the thioether-containing compounds contributed higher antibacterial activities against $R$. solanacearum. Furthermore, title compounds E3, E11, E24 and G2 showed good insecticidal activities of $75 \%, 70 \%, 70 \%$ and $75 \%$, respectively.
\end{abstract}

\section{Introduction}

Crop diseases caused by bacteria, fungi, viruses, nematodes and oomycetes have posed a huge challenge for crop production, so that it is hard to provide sufficient food for the growing population. ${ }^{1,2}$ Particularly, rice bacterial leaf blight caused by Xanthomonas oryzae pv. oryzae (Xoo) can reduce rice yields by $80 \% .^{3,4}$ Tobacco bacterial wilt caused by Ralstonia solanacearum $(R$. solanacearum), is another devastating disease. ${ }^{5}$ Pesticides play a crucial role in controlling crop diseases for agricultural cultivating systems, rapidly increasing the crop yields and food production. ${ }^{\mathbf{1 , 6}}$ However, along with the resistance and cross resistance, the efficiencies of many pesticides have gradually reduced. Currently, because of the potential environmental, ecological and health risks, some pesticides have been gradually banned and withdrawn from the market. For example, bismerthiazol, used as a bactericide against rice bacterial blight, was banned by the Ministration of Agriculture, P. R. China due to its harmful effects towards some creatures.

State Key Laboratory Breeding Base of Green Pesticide and Agricultural Bioengineering, Key Laboratory of Green Pesticide and Agricultural Bioengineering, Ministry of Education, Research and Development Center for Fine Chemicals, Guizhou University, Huaxi District, Guiyang 550025, P. R. China. E-mail: wujian2691@126.com; jwu6@gzu.edu.cn

$\dagger$ Electronic supplementary information (ESI) available: The copies of ${ }^{1} \mathrm{H}$ NMR, ${ }^{19} \mathrm{~F}$ NMR, ${ }^{13} \mathrm{C}$ NMR and HR-MS spectrograms for all the synthesized compounds. See DOI: 10.1039/d0ra07301f

\$ Co-first author for the manuscript.
Consequently, the development of eco-friendly pesticides with novel action modes is urgently needed.

Sulfur element is a crucial part of proteins and amino acids. It can be found in many secondary metabolites in living organisms, and exits also in many bio-active compounds (Fig. 1) with broaden biological activities, ${ }^{7-14}$ especially using for anticancer, ${ }^{15-18}$ anti-HIV, ${ }^{19,20}$ and treating acid-related disorder, ${ }^{21}$ and also using for the inhibitors of topoisomerase $1,,^{22}$ anhydrase II, ${ }^{23}$ mutated B-Raf, ${ }^{24,25}$ cyclooxygenase- $2 .{ }^{26,27}$ Particularly, compounds containing thioether, sulfone or sulfoxide moieties could exhibit significantly anti-bacterial, ${ }^{28-32}$ anti-fungal, ${ }^{33,34}$ herbicidal $^{35}$ and insecticidal ${ }^{36,37}$ activities for crop protection. Thus, sulfur-containing molecules show promising properties for drug design and medicinal chemistry. ${ }^{38-40}$

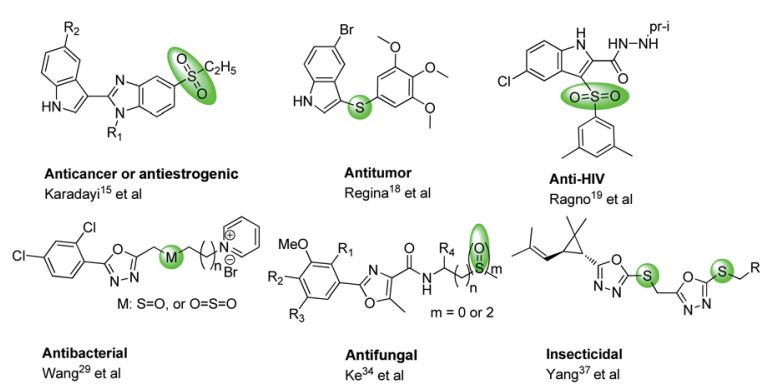

Fig. 1 Some bio-active molecules containing thioether, sulfoxide or sulfone. 
Over decades, trifluoromethylpyridine ring, a special fluorinated nitrogen heterocycle, has been a hot spot for the creation of novel pesticides. ${ }^{41-43}$ For the period 2000-2017, among a total 166 ISO common name proposals, $10(6 \%)$ contain a trifluoromethylpyridine, including 3 fungicides, 2 herbicides and 5 insecticides. ${ }^{43}$ Our previous works ${ }^{44-46}$ also revealed that some compounds containing trifluoromethyl pyridine showed excellent anti-virus, anti-bacterial and insecticidal activities.

Consequently, considering the concepts mentioned above, this work focused on the synthesis of trifluoromethylpyridine amide derivatives containing the thioether, sulfoxide or sulfone substructure, and their biological evaluation. Their primary structure-activity relationship for these novel trifluoromethylpyridine amide derivatives was also discussed.

\section{Results and discussion}

\subsection{Design}

The commercial fungicides such as fluopicolide and fluopyram (Fig. 2) are typical trifluoromethylpyridine derivatives. ${ }^{43}$ Our previous work has revealed that trifluoromethyl pyridinamide derivatives containing a structure of " $-\mathrm{S}=\mathrm{N}-\mathrm{CN}$ " showed significantly bactericidal activities. ${ }^{46}$ Wang and co-workers ${ }^{29}$ has reported that some novel sulfur contained compounds can be used as potential antibacterial agents. ${ }^{29}$ Thus as shown in Fig. 2, this work sought to modify the previous structure through changing the "-S=N-CN" to "-S-", "-SO ${ }^{2}-$ " or "-SO-" to obtain a series of novel thioether-containing compounds E1-E26. Then, the chemoselectivities of sulfone-containing compounds F1-F10 and sulfoxide-containing compounds G1-G16, were obtained by the oxidation of compounds E1-E26 in different conditions (Scheme 1). Their antibacterial activities against Xoo and $R$. solanacearum, and insecticidal activities against $P$. xylostella were evaluated. Desirably, some synthesized compounds could show higher antibacterial activities than that of commercialized thiodiazole copper and bismerthiazol. It's the first time that trifluoromethylpyridine amide derivatives containing the sulfur moiety were designed and synthesized for anti-bacterial and insecticidal applications.

\subsection{Chemistry}

According to the reported methods, ${ }^{29,47,48}$ the title compounds E1-E26, F1-F10 and G1-G16 could be easily obtained as shown in Scheme 1. The thioether-containing compounds E1-E26 were

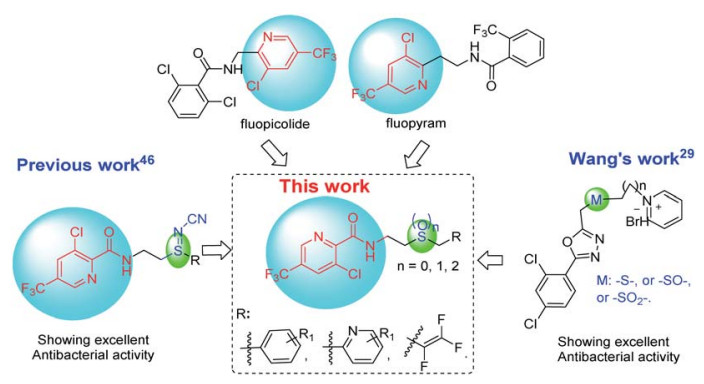

Fig. 2 The design of the title compounds.

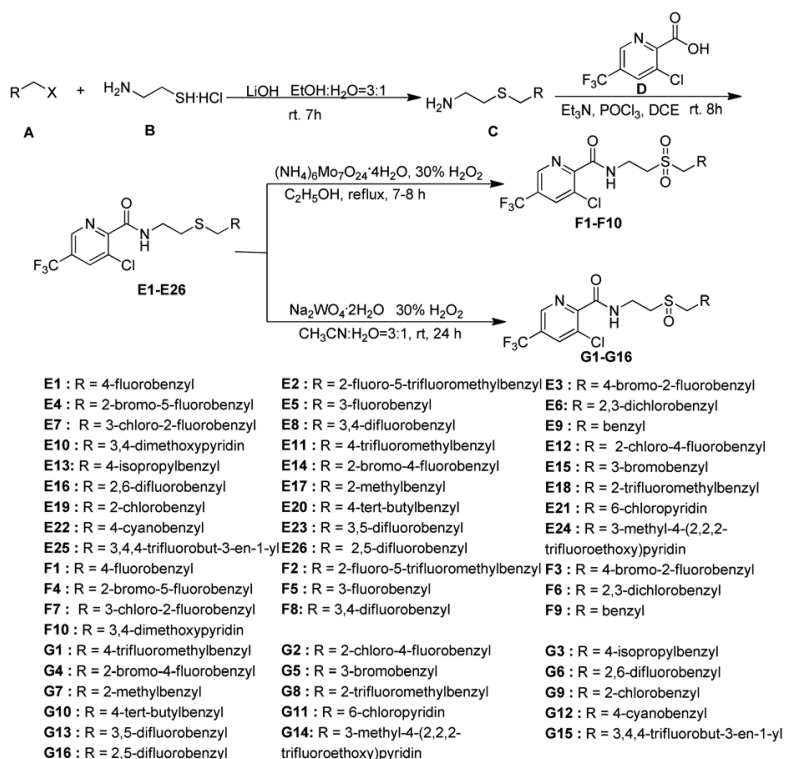

Scheme 1 The synthetic route of the title compounds E1-E26, F1F10, and G1-G16.

firstly synthesized via two steps. Firstly, haloalkane (A) was treated with aminoethyl mercaptan (B) using $\mathrm{LiOH}$ as base and the mixture of ethanol and $\mathrm{H}_{2} \mathrm{O}$ in a ratio of $3: 1$ as solvent under room temperature (rt) to obtain differently substituted 2(ethylthio)amines (C). ${ }^{\mathbf{2 9 , 4 7 , 4 8}}$ After being activated by $\mathrm{POCl}_{3}, 3$ chloro-5-(trifluoromethyl)picolinic acid (D) condensed with intermediate $\mathbf{C}$ to obtain thioether-containing compounds E1E26. ${ }^{29,47,48}$ Thioether-containing compounds E1-E10 were then converted to corresponding sulfone-containing compounds F1F10 in the presence of ammonium molybdate, $30 \% \mathrm{H}_{2} \mathrm{O}_{2}$ as oxidant and ethanol as solvent at $100{ }^{\circ} \mathrm{C} .{ }^{47,48}$ Different with the synthesis of sulfone compounds F1-F10, sulfoxide-containing compounds G1-G16 were obtained through the oxidation of E11-E26 in the presence of sodium tungstate dehydrate, 30\% $\mathrm{H}_{2} \mathrm{O}_{2}$ as oxidant and the mixture of acetonitrile and water in a ratio of $3: 1$ as solvent at rt. $^{47,48}$

The title thioether-containing compounds E1-E26, sulfonecontaining compounds F1-F10 and sulfoxide-containing compounds G1-G16 were characterized by the ${ }^{1} \mathrm{H}$ NMR, ${ }^{19} \mathrm{~F}$ NMR, ${ }^{13} \mathrm{C}$ NMR and HR-MS. Taking sulfone-containing compound F1 as an example, in the ${ }^{1} \mathrm{H}$ NMR spectrum, the proton near " $\mathrm{N}$ " atom of trifluoromethylpyridine ring appeared as a doublet at $\delta 8.72 \mathrm{ppm}$. The proton of -CONH- was split into a triplet at $\delta 8.40 \mathrm{ppm}$. Another proton of trifluoromethylpyridine ring appeared also as a doublet at $\delta$ 8.07. The four protons of benzene ring were characterized as two multiples at $\delta 7.33-7.23$ and $\delta 7.15-7.00$. The protons of methylene near the benzene ring appeared as a quartet at $\delta 4.03$. The protons of methylene near the carbonyl appeared as multiple at $\delta 3.11-2.77$, and the protons of methylene appeared at $\delta 3.96$ as double doublets. In ${ }^{13} \mathrm{C}$ NMR spectrum, the carbons near "- $\mathrm{CF}_{3}$ " or " $\mathrm{F}$ " were all split into quartets due to the coupling coefficients of "F". For instance, the carbon of " $-\mathrm{CF}_{3}$ " group was split into a quartet at $\delta_{\mathrm{C}} 122.1 \mathrm{ppm}$ with the coupling constant 
of $\left({ }^{1} J_{\mathrm{F}-\mathrm{C}}\right) 273.3 \mathrm{~Hz}$. Carbon at the position 5 in the pyridine, was split into another quartet with coupling constant of $34.1 \mathrm{~Hz}$ at $\delta_{\mathrm{C}}$ 129.4. Two carbons at the position 4 and 6 of trifluoromethylpyridine, were also split into two quartets with smaller coupling constants. Other carbons near the atom " $F$ " could also be split with different coupling constants. In the ${ }^{19} \mathrm{~F}$ NMR spectra, the fluorine of " $-\mathrm{CF}_{3}$ " appeared at the shift of $-62.57 \mathrm{ppm}$, and the fluorine on the benzene ring appeared at the shift of $-112.80 \mathrm{ppm}$.

\subsection{Preliminary in vitro antibacterial activity test}

According to the reported method, ${ }^{49}$ the method of turbidity was adopted to evaluate the antibacterial activities of title compounds against Xanthomonas oryzae pv. oryzae (Xoo), Ralstonia solanacearum (R. solanacearum). The commercial thiodiazole copper (TC) and bismerthiazol (BT) were used as the positive controls. The results shown in Table 1 revealed that some of the synthesized compounds showed higher activities against Xoo and $R$. solanacearum than that of commercial bactericides at the

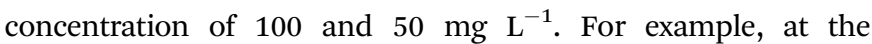
concentration of $50 \mathrm{mg} \mathrm{L}{ }^{-1}$, compounds E20 ( $\mathrm{R}$ is 4-tert-butylbenzyl), E15 ( $\mathrm{R}$ is 3-bromobenzyl), E9 ( $\mathrm{R}$ is benzyl), E16 ( $\mathrm{R}$ is 2,6difluorobenzyl), E13 ( $\mathrm{R}$ is 4-isopropylbenzyl) and E24 ( $\mathrm{R}$ is 3methyl-4-(2,2,2-trifluoroethoxy)pyridine) showed good activities against Xoo of 35\%, 35\%, 33\%, 33\%, 32\% and 31\% respectively, which are close to that of BT (31\%). Desirably, when two electron withdraw groups, 3,4-dimethoxypyridine, substituted in the phenyl, sulfone-containing compound F10 exhibited the highest activities of $53 \%\left(100 \mathrm{mg} \mathrm{L}^{-1}\right)$ and $42 \%\left(50 \mathrm{mg} \mathrm{L}^{-1}\right)$ against Xoo, which are slightly higher than that of TC $(53 \%, 39 \%)$ and BT $(51 \%$, 31\%). Sulfone-containing compounds F1-F10 showed the different activities against Xoo as follows: 3,4-dimethoxypyridin (F10) > benzyl (F9) > 4-bromo-2-fluorobenzyl (F3) > 4-fluorobenzyl (F1) > 3-fluorobenzyl (F5) > 2,3-dichlorobenzyl (F6) > 2-fluoro-5trifluoromethylbenzyl (F2) > 2-bromo-5-fluorobenzyl (F4) $>3$ chloro-2-fluorobenzyl (F7) > 3,4-difluorobenzyl (F8). Among sulfone-containing compounds, compounds F3 (31\%), F5 (31\%) and F9 (32\%) showed activities of $31 \%, 31 \%$ and $32 \%$ respectively against $X O o$ at $50 \mathrm{mg} \mathrm{L}^{-1}$, which are close to than that of BT $(31 \%)$. Among sulfoxide-containing compounds, compounds G5 where R is 3-bromobenzyl and $\mathbf{G 1 6}$ where $\mathrm{R}$ is 2,5-difluorobenzyl showed activities of $32 \%$ and $35 \%$, respectively against $X o o$ at $50 \mathrm{mg} \mathrm{L}^{-1}$, which are closed to that of BT (31\%). The majority of oxidized compounds (sulfone or sulfoxide-containing compounds) could show higher activities against Xoo, compared with the thioethercontaining compounds. For example, oxidizing thioethercontaining compounds E3 (9\%), E4 (13\%), E7 (7\%) and E17 (4\%) to corresponding F3 (47\%), F4 (32\%), F7 (31\%) and G7 (36\%)

Table 1 Antibacterial activities of title compounds E1-E26, F1-F10 and G1-G16 against Xoo and R. solanacearum

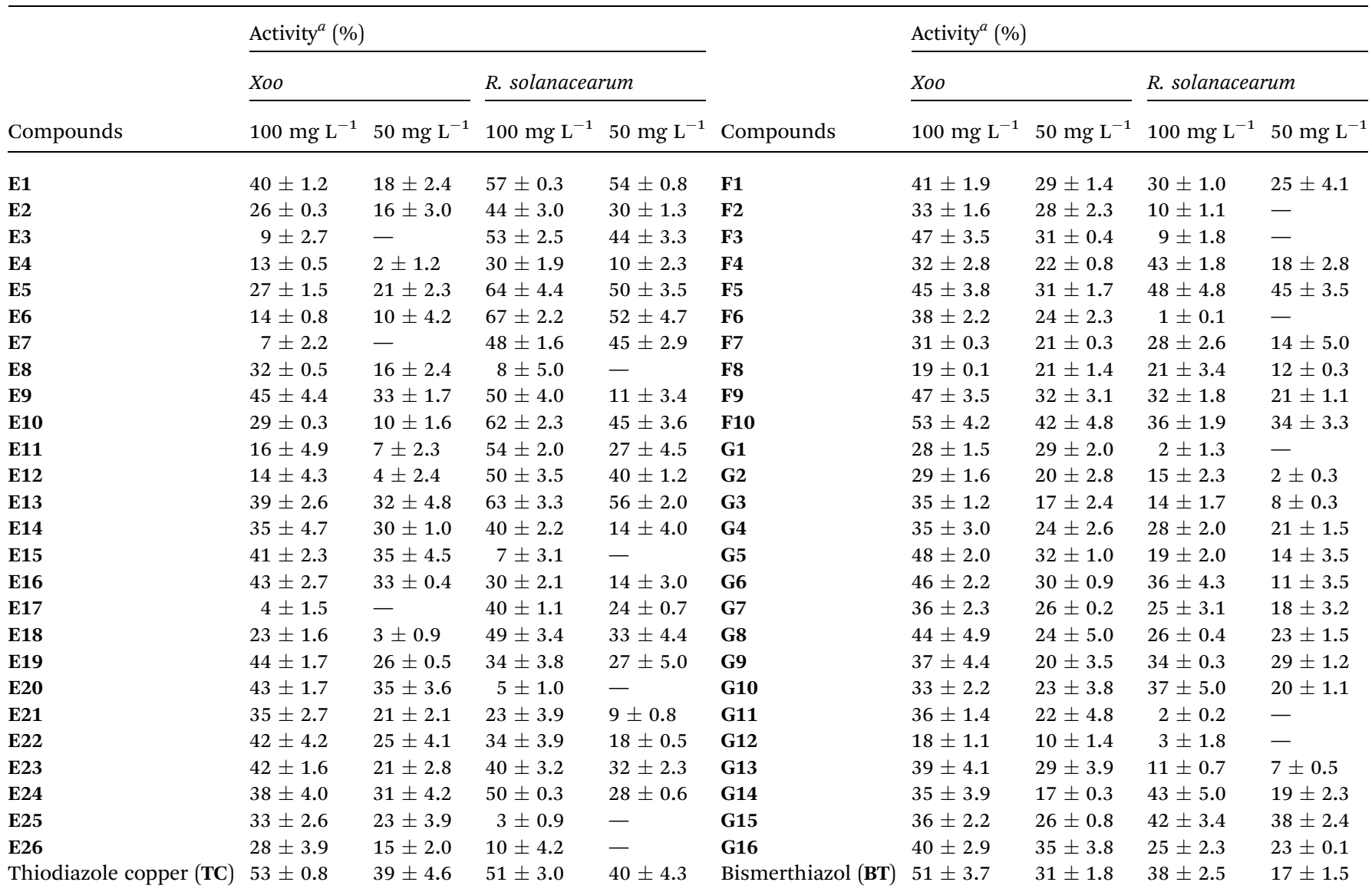

${ }^{a}$ The antibacterial activities are mean of three independent experiments. 
could provide $38 \%, 26 \%, 24 \%$ and $32 \%$ higher activities against Xoo at $100 \mathrm{mg} \mathrm{L}^{-1}$, respectively. However, compounds E8 (32\%), E22 (42\%) and E24 (38\%) showed higher activities against Xoo than that of corresponding oxidized compounds F8 (19\%), G9 (18\%) and G24 (28\%). Thioether-containing compounds E13 (39\%), E19 (44\%), E20 (43\%) and E23 (42\%) showed slightly higher activities against $X o o$ at $100 \mathrm{mg} \mathrm{L}^{-1}$ than that of corresponding oxidized compounds G3 (35\%), G9 (37\%), G10 (33\%) and G13 (39\%). The rest of oxidized compounds owned higher activities against Xoo than that of corresponding thioethercontaining compounds. Regarding $R$. solanacearum, thioethercontaining compounds E1 (57\%, 54\%), E3 (53\%, 44\%), E5 (64\%, 50\%), E6 (67\%, 52\%), E10 (62\%, 45\%), E11 (54\%) and E13 $(63 \%, 56 \%)$ exhibited higher activities than that of TC $(51 \%, 40 \%)$ and much higher activities than that of BT $(38 \%, 17 \%)$ at 100 or $50 \mathrm{mg} \mathrm{L}^{-1}$. According to their activities, the $\mathrm{R}$ groups of them can be sorted as follows: 2,3-dichlorobenzyl (E6) > 3-fluorobenzyl (E5) $>$ 4-isopropylbenzyl (E13) > 3,4-dimethoxypyridin (E10) > 4-fluorobenzyl (E1) > 4-trifluoromethylbenzyl (E11) > 4-bromo-2fluorobenzyl (E3). At 100 or $50 \mathrm{mg} \mathrm{L}^{-1}$, there are other thioether-containing compounds showing higher activities against $R$. solanacearum than that of BT $(38 \%, 17 \%)$, including $\mathrm{R}$ groups are 3-methyl-4-(2,2,2-trifluoroethoxy)pyridine (E24, 50\%, 28\%), 2-trifluoromethylbenzyl (E18, 49\%, 33\%), 3-chloro-2fluorobenzyl (E7, 48\%, 45\%), 2-fluoro-5-trifluoromethylbenzyl (E2, 44\%, 30\%), 3,5-difluorobenzyl (E23, 40\%, 32\%), 2-bromo-4fluorobenzyl (E14, 40\%) and 2-methylbenzyl (E17, 40\%, 24\%). Sulfone-containing compounds F4 (43\%) and F5 (48\%) could also show higher activities than that of BT against $R$. solanacearum. Among the sulfoxide-containing compounds, compounds $\mathbf{G 1 4}$ (43\%) and G15 (42\%) showed higher activities against $R$. solanacearum than that of BT. Their R groups are 3-methyl-4-(2,2,2trifluoroethoxy)pyridine and 3,4,4-trifluorobut-3-en-1-yl, respectively. Sulfone-containing compound F4 (43\%) and sulfoxidecontaining compounds G6 (36\%), G10 (37\%), G15 (42\%), G16 $(25 \%)$ showed higher activities against $R$. solanacearum than that of corresponding thioether-containing compounds E4 (30\%), E16 (30\%), E20 (5\%), E25 (3\%) and E26 (10\%). But the rest of sulfonecontaining compounds or sulfoxide-containing compounds exhibited much lower activities than that of corresponding thioether-containing compounds, which is totally different with the activities against Xoo. Particularly, when $\mathrm{R}$ is 2,3-dichlorobenzyl, thioether-containing compound E6 could show the highest activity (67\%), which is much higher than that of TC and BT, but the corresponding oxidized sulfone-containing compound F6 owned no activity (1\%) against $R$. solanacearum. In addition, thioether-containing compound E13 also exhibited much higher activity (63\%) against $R$. solanacearum than that of both TC and BT, however, sulfoxide-containing compound G3, the oxidized product of E13, are almost no activity against $R$. solanacearum.

\subsection{The $\mathrm{EC}_{50}$ values of active title compounds against $\mathrm{Xoo}$ or R. solanacearum}

The half-maximal effective concentration $\left(\mathrm{EC}_{50}\right)$ values of sulfone-containing compound F10 against Xoo, and thioethercontaining compounds E1, E3, E5, E6, E10, E11, and E13 against $R$. solanacearum were further evaluated. The results listed in Table 2 indicated the $\mathrm{EC}_{50}$ value against Xoo of sulfonecontaining compound $\mathbf{F 1 0}$ is $83 \mathrm{mg} \mathrm{L}^{-1}$, which is much lower than that of TC $\left(97 \mathrm{mg} \mathrm{L}^{-1}\right)$ and BT $\left(112 \mathrm{mg} \mathrm{L}^{-1}\right)$. Furthermore, the $\mathrm{EC}_{50}$ values against $R$. solanacearum of thioether-containing compounds E6 and $\mathbf{E 1 3}$ are $41 \mathrm{mg} \mathrm{L}^{-1}$ and $40 \mathrm{mg} \mathrm{L}^{-1}$ respectively, which are twice lower than that of TC $\left(87 \mathrm{mg} \mathrm{L}^{-1}\right)$ and third lower than that of BT $\left(124 \mathrm{mg} \mathrm{L}^{-1}\right)$. Thioether-containing compounds E1, E3, E5, E10 and E11 had the EC $_{50}$ values of 53, $75,53,78$ and $73 \mathrm{mg} \mathrm{L}^{-1}$ respectively, which are also much lower than that of TC and $\mathbf{B T}$.

\subsection{Insecticidal activity test}

The insecticidal activities of synthesized compounds against $P$. xylostella are shown in Table 3 . The chlorpyrifos and avermectin were used as positive controls. The results (Table 3) revealed that some compounds could show moderate insecticidal activities. Thioether-containing compound E3 where R is 4-bromo-2fluorobenzyl showed the highest activity of $75 \%$ against $P$. xylostella, but the activity could sharply decrease after being

Table 2 The $\mathrm{EC}_{50}$ values of title compounds against $X_{00}$ or $R$. solanacearum

\begin{tabular}{|c|c|c|c|c|c|c|c|}
\hline Compounds & Regression equation & $R^{2}$ & $\mathrm{EC}_{50}{ }^{a}\left(\mathrm{mg} \mathrm{L}^{-1}\right)$ & Compounds & $\begin{array}{l}\text { Regression } \\
\text { equation }\end{array}$ & $R^{2}$ & $\mathrm{EC}_{50}{ }^{a}\left(\mathrm{mg} \mathrm{L}^{-1}\right)$ \\
\hline F10 & $y=0.8557 x+3.3573$ & 1.00 & $83 \pm 0.1$ & E1 & $y=0.7768 x+3.661$ & 0.98 & $53 \pm 0.3$ \\
\hline Thiodiazole copper (TC) & $y=0.996 x+3.065$ & 0.99 & $97 \pm 1.2$ & E3 & $y=2.4159 x+0.4676$ & 0.94 & $75 \pm 0.5$ \\
\hline \multirow[t]{5}{*}{ Bismerthiazol (BT) } & $y=2.5861 x-0.0104$ & 0.97 & $112 \pm 1.2$ & E5 & $y=1.4452 x+2.5102$ & 1.00 & $53 \pm 0.9$ \\
\hline & & & & E11 & $y=1.3523 x+2.4812$ & 0.99 & $73 \pm 1.2$ \\
\hline & & & & E13 & $y=0.9336 x+3.507$ & 0.99 & $40 \pm 2.1$ \\
\hline & & & & Thiodiazole copper (TC) & $y=1.6934 x+1.7154$ & 0.94 & $87 \pm 1.1$ \\
\hline & & & & Bismerthiazol (BT) & $y=2.0182 x+0.7772$ & 0.97 & $124 \pm 1.3$ \\
\hline
\end{tabular}

${ }^{a}$ Each experiment of $\mathrm{EC}_{50}$ value is performed in triplicates. 
oxidized into corresponding sulfone-containing compound F3 (10\%). When R was changed to 4-trifluoromethylbenzyl (E11) or 3-methyl-4-(2,2,2-trifluoroethoxy)pyridine (E24), the activity could slightly decrease to $70 \%$. Thioether-containing compounds E5 and E12 both showed the activities of 55\% against $P$. xylostella, and their R groups are 3-fluorobenzyl and 2-chloro-4-fluorobenzyl, respectively. Thioether-containing compounds E1 (2-bromo-5-fluorobenzyl), E4 (4-fluorobenzyl), E7 (3-chloro-2-fluorobenzyl), E15 (3-bromobenzyl) all showed activities of $50 \%$. The rest of thioether-containing compounds showed lower activities less than 50\%. In addition, the insecticidal activities of sulfone-containing compounds could be sorted as follows: 3-chloro-2-fluorobenzyl (F7) > 2-fluoro-5trifluoromethylbenzyl (F2) > 2-bromo-5-fluorobenzyl (F4) > 4fluorobenzyl (F1) > 2,3-dichlorobenzyl (F6) = 3,4-difluorobenzyl (F8) = benzyl (F9) = 3,4-dimethoxypyridin (F10) > 4-bromo-2fluorobenzyl (F3) > 3-fluorobenzyl (F5). Specially, sulfonecontaining compounds F2, F7, F9 and F10 all showed higher activities than that of corresponding thioether-containing compounds E2, E7, E9 and E10, but the rest of sulfonecontaining compounds all showed activities less than that of corresponding thioether-containing compounds. When $\mathrm{R}$ is 2chloro-4-fluorobenzyl, sulfoxide-containing compound G2 showed activity of $75 \%$. Sulfoxide-containing compounds G3, G6 and G7 showed the activities of $60 \%, 60 \%$ and $50 \%$ respectively, which are all higher than that of corresponding

Table 3 Insecticidal activities of title compounds against $P$. xylostella

\begin{tabular}{llll}
\hline Compounds & $\begin{array}{l}\text { Activity }^{a}(\%) \\
\text { at } 500 \mathrm{mg} \mathrm{L}^{-1}\end{array}$ & Compounds & $\begin{array}{c}\text { Activity }^{a}(\%) \\
\text { at } 500 \mathrm{mg} \mathrm{L}^{-1}\end{array}$ \\
\hline E1 & $50 \pm 0$ & F1 & $35 \pm 0$ \\
E2 & $45 \pm 2.9$ & F2 & $50 \pm 0$ \\
E3 & $75 \pm 0$ & F3 & $10 \pm 3.3$ \\
E4 & $50 \pm 0$ & F4 & $40 \pm 3.3$ \\
E5 & $55 \pm 0$ & F5 & $10 \pm 0$ \\
E6 & $40 \pm 2.9$ & F6 & $30 \pm 3.3$ \\
E7 & $50 \pm 3.3$ & F7 & $60 \pm 0$ \\
E8 & $30 \pm 0$ & F8 & $30 \pm 0$ \\
E9 & $10 \pm 5$ & F9 & $30 \pm 0$ \\
E10 & $10 \pm 0$ & F10 & $30 \pm 0$ \\
E11 & $70 \pm 0$ & G1 & $30 \pm 0$ \\
E12 & $55 \pm 3.3$ & G2 & $75 \pm 0$ \\
E13 & $30 \pm 2.9$ & G3 & $60 \pm 0$ \\
E14 & $10 \pm 2.9$ & G4 & $40 \pm 0$ \\
E15 & $50 \pm 0$ & G5 & $30 \pm 0$ \\
E16 & $20 \pm 0$ & G6 & $60 \pm 0$ \\
E17 & $40 \pm 0$ & G7 & $50 \pm 2.9$ \\
E18 & $30 \pm 0$ & G8 & $20 \pm 0$ \\
E19 & $20 \pm 0$ & G9 & $20 \pm 0$ \\
E20 & $30 \pm 5$ & G10 & $10 \pm 0$ \\
E21 & $20 \pm 3.3$ & G11 & $30 \pm 0$ \\
E22 & $30 \pm 0$ & G12 & $10 \pm 0$ \\
E23 & $35 \pm 0$ & G13 & $20 \pm 0$ \\
E24 & $70 \pm 0$ & G14 & $10 \pm 3.3$ \\
E25 & $10 \pm 0$ & G15 & $40 \pm 0$ \\
E26 & $10 \pm 0$ & G16 & $30 \pm 3.3$ \\
Chlorpyrifos & $100 \pm 0$ & Avermectin & $100 \pm 0$ \\
& & &
\end{tabular}

${ }^{a}$ The each insecticidal test were performed in triplicates. thioether-containing compounds E13, E16 and E17. The activities of the rest of sulfoxide-containing compounds are all less than $50 \%$.

\section{Conclusion}

A series of sulfur-containing trifluoromethylpyridine amide derivatives has been designed and synthesized. Their antibacterial activities against Xanthomonas oryzae pv. oryzae (Xoo), Ralstonia solanacearum ( $R$. solanacearum) and insecticidal activities against $P$. xylostella were evaluated. Notably, sulfonecontaining compound F10 (53\%, 42\%) showing the highest activity against $X o o$ had the $\mathrm{EC}_{50}$ of $83 \mathrm{mg} \mathrm{L}^{-1}$, which is much lower than that of TC $\left(97 \mathrm{mg} \mathrm{L}^{-1}\right)$ and BT $\left(112 \mathrm{mg} \mathrm{L}^{-1}\right)$. Thioether-containing compounds E1 (57\%, 54\%), E3 (53\%, $44 \%)$, E5 (64\%, 50\%), E6 (67\%, 52\%), E9 (50\%, 11\%), E10 (62\%, 45\%), E11 (54\%, 27\%), and E13 (53\%, 44\%) showed higher activities than that of TC $(51 \%, 40 \%)$ showed excellent antibacterial activities against $R$. solanacearum with $\mathrm{EC}_{50}$ values ranging from $40-73 \mathrm{mg} \mathrm{L}^{-1}$, which are all much lower than that of TC $\left(87 \mathrm{mg} \mathrm{L}^{-1}\right)$ and BT $\left(124 \mathrm{mg} \mathrm{L}^{-1}\right)$. Generally, most of oxidized compounds could show higher activities against Xoo than that of corresponding thioether-containing compounds, but most of thioether-containing compounds contributed higher activities against $R$. solanacearum. Furthermore, compounds E3, E11, E24 and G2 showed also moderate insecticidal activities of $75 \%, 70 \%, 70 \%$ and $75 \%$, respectively.

\section{Experimental section}

\subsection{Materials and methods}

All reagents and solvents were purchased from Accela Chem-Bio Co., Ltd (Shanghai, China) and Innochem Co., Ltd (Beijing, China). Melting points of the synthesized compounds were measured using a XT-4 binocular microscope (Beijing Tech Instrument Co., China). Using $\mathrm{CDCl}_{3}$ as solvent, the spectra of ${ }^{1} \mathrm{H},{ }^{19} \mathrm{~F}$ and ${ }^{13} \mathrm{C}$ NMR of title compounds were recorded on AVANCE III HD 400M NMR (Bruker Corporation, Switzerland) spectrometer operating at room temperature. HR-MS was recorded on an Orbitrap LC-MS instrument (Q-Exative, Thermo Scientific $^{\mathrm{TM}}$, and American). The course of the reactions was monitored by TLC.

\subsection{Synthetic procedures}

4.2.1 Synthesis of substituted aminoethyl sulfide (C). According to the reported literatures, ${ }^{\mathbf{4 7}, 48}$ substituted intermediate $\mathbf{C}$ could be easily obtained as shown in Scheme 1. Taking 2-((4-fluorobenzyl)thio)ethanamine as an example, to a mixture of $\mathrm{LiOH}(72.63 \mathrm{mmol})$ resolving in $15 \mathrm{~mL}$ water and $\mathrm{EtOH}$ $(45 \mathrm{~mL})$ stirred at room temperature was added 2-aminoethyl mercaptan (B, $34.58 \mathrm{mmol}$ ). Subsequently, 1-(chloromethyl)-4fluorobenzene (A, $34.58 \mathrm{mmol}$ ) was added dropwise and stirred at room temperature for about $7 \mathrm{~h}$. The reaction was monitored by TLC. After the completion of the reaction, the reaction mixture was concentrated under reduced pressure, and the residue was extracted with dichloromethane and water. The 
organic phase was washed with $\mathrm{NaOH}$ solution to provide a crude production, which was purified using silica gel (200-300 mesh) column chromatography with dichloromethane/ methanol $(20: 1)$.

4.2.2 The synthesis of thioether-containing compounds E1-E26. ${ }^{29,47,48}$ Taking E1 as an example, 2-(((2-aminoethyl)thio) methyl)-5-fluorobenzene-1-ylium (C, $2.64 \mathrm{mmol}), 3$-chloro-5(trifluoromethyl)picolinic acid (D, $2.64 \mathrm{mmol}$ ) and $\mathrm{Et}_{3} \mathrm{~N}$ (2.64 $\mathrm{mmol})$ were added in one portion using 1,2-dichloroethane (DCE, $6 \mathrm{~mL}$ ) as solvent, which was stirred at room temperature. Subsequently, $\mathrm{POCl}_{3}$ diluted by DCE was added dropwise and refluxed for $8 \mathrm{~h}$. The resulted mixture was concentrated under reduced pressure, and washed with $\mathrm{Na}_{2} \mathrm{CO}_{3}$. The resulting solid was filtrated and washed with water to provide crude product, which was purified by silica gel (200300 mesh) column chromatography with ethyl acetate/ petroleum ether $(1: 3)$. Along with similar method, thioethercontaining compounds E2-E26 could be also obtained. The spectral data of E1-E26 are listed below, and the spectra are shown in the ESI data. $\dagger$

3-Chloro-N-(2-((4-fluorobenzyl)thio)ethyl)-5-(trifluoromethyl) picolinamide (E1). Yield 83\%; yellow solid; mp 96-97 ${ }^{\circ} \mathrm{C} .{ }^{1} \mathrm{H}$ NMR (400 MHz, $\left.\mathrm{CDCl}_{3}\right) \delta 8.72(\mathrm{~s}, 1 \mathrm{H}$, pyridine- $\mathrm{H}), 8.08(\mathrm{~s}, 1 \mathrm{H}$, pyridine-H), 7.99 (s, $1 \mathrm{H}, \mathrm{CO}-\mathrm{NH}), 7.30(\mathrm{dd}, J=8.4,5.4 \mathrm{~Hz}, 2 \mathrm{H}$, $\mathrm{Ar}-\mathrm{H}), 6.98$ (t, $J=8.6 \mathrm{~Hz}, 2 \mathrm{H}, \mathrm{Ar}-\mathrm{H}), 3.75\left(\mathrm{~s}, 2 \mathrm{H},-\mathrm{CH}_{2}\right), 3.62$ (q, $\left.=6.4 \mathrm{~Hz}, 2 \mathrm{H},-\mathrm{CH}_{2}\right), 2.69\left(\mathrm{t}, J=6.5 \mathrm{~Hz}, 2 \mathrm{H},-\mathrm{CH}_{2}\right) \cdot{ }^{13} \mathrm{C} \mathrm{NMR}(100$ $\left.\mathrm{MHz}, \mathrm{CDCl}_{3}\right) \delta 162.3,161.9(\mathrm{~d}, J=245.8 \mathrm{~Hz}), 149.1,142.8(\mathrm{q}, J=$ $3.8 \mathrm{~Hz}), 137.7$ (q, $J=3.6 \mathrm{~Hz}), 133.7$ (d, $J=3.2 \mathrm{~Hz}), 132.2,130.4$ $(\mathrm{d}, J=8.1 \mathrm{~Hz}), 129.3(\mathrm{q}, J=34.0 \mathrm{~Hz}), 122.2(\mathrm{q}, J=273.4 \mathrm{~Hz})$, $115.5(\mathrm{~d}, J=21.5 \mathrm{~Hz}), 38.4,35.2,30.9 .{ }^{19} \mathrm{~F}$ NMR $(376 \mathrm{MHz}$, $\left.\mathrm{CDCl}_{3}\right) \delta-62.52,-115.22$. HRMS: $[\mathrm{M}+\mathrm{H}]^{+}$calcd for $\mathrm{C}_{16} \mathrm{H}_{14}{ }^{-}$ $\mathrm{ClF}_{4} \mathrm{~N}_{2} \mathrm{OS}$ : 393.04460; found: 393.04370.

3-Chloro-N-(2-((2-fluoro-5-(trifluoromethyl)benzyl)thio)ethyl)-5(trifluoromethyl)picolinamide (E2). Yield 83\%; yellow solid; mp 101-103 ${ }^{\circ} \mathrm{C} .{ }^{1} \mathrm{H}$ NMR $\left(400 \mathrm{MHz}, \mathrm{CDCl}_{3}\right) \delta 8.73$ (s, 1H, pyridine$\mathrm{H}), 8.08$ (d, $J=1.3 \mathrm{~Hz}, 2 \mathrm{H}$, pyridine-H, CO-NH), 7.69 (dd, $J=$ 6.7, $2.0 \mathrm{~Hz}, 1 \mathrm{H}, \mathrm{Ar}-\mathrm{H}), 7.54-7.49(\mathrm{~m}, 1 \mathrm{H}, \mathrm{Ar}-\mathrm{H}), 7.16(\mathrm{t}, J=$ $8.9 \mathrm{~Hz}, 1 \mathrm{H}, \mathrm{Ar}-\mathrm{H}), 3.85$ (s, 2H, $-\mathrm{CH}_{2}$ ), 3.69 (q, $J=6.4 \mathrm{~Hz}, 2 \mathrm{H}$, $\left.-\mathrm{CH}_{2}\right), 2.77\left(\mathrm{t}, J=6.5 \mathrm{~Hz}, 2 \mathrm{H},-\mathrm{CH}_{2}\right) .{ }^{13} \mathrm{C} \mathrm{NMR}\left(100 \mathrm{MHz}, \mathrm{CDCl}_{3}\right)$ $\delta 162.5(\mathrm{dd}, J=252.5,1.3 \mathrm{~Hz}), 162.3,148.9(\mathrm{~d}, J=1.0 \mathrm{~Hz}), 142.9$ $(\mathrm{q}, J=3.8 \mathrm{~Hz}), 137.7$ (q, $J=3.6 \mathrm{~Hz}), 132.2,129.3(\mathrm{dd}, J=$ $102.0 \mathrm{~Hz}, J=34.0 \mathrm{~Hz}$ ), 128.6-128.0 (m), $127.0(\mathrm{dd}, J=33.1,3.6$ $\mathrm{Hz}), 126.7$ (d, $J=16.0 \mathrm{~Hz}), 126.4(\mathrm{dt}, J=13.0,3.7 \mathrm{~Hz}), 123.6$ (q, $J$ $=272.0 \mathrm{~Hz}), 122.2(\mathrm{q}, J=273.4 \mathrm{~Hz}), 116.2(\mathrm{~d}, J=23.4 \mathrm{~Hz}), 38.3$, 31.5, 28.5 (d, $J=2.7 \mathrm{~Hz}) .{ }^{19} \mathrm{~F}$ NMR $\left(376 \mathrm{MHz} \mathrm{CDCl}_{3}\right) \delta-61.97$, $-62.57, \delta-112.57(\mathrm{dd}, J=14.2,7.8 \mathrm{~Hz})$. HRMS: $[\mathrm{M}+\mathrm{H}]^{+}$calcd for $\mathrm{C}_{17} \mathrm{H}_{13} \mathrm{ClF}_{7} \mathrm{~N}_{2} \mathrm{OS}$ : 461.03199; found: 461.03098 .

$\mathrm{N}$-(2-((4-Bromo-2-fluorobenzyl)thio)ethyl)-3-chloro-5-

(trifluoromethyl)picolinamide (E3). Yield 77\%; brown solid; mp 95-96 ${ }^{\circ} \mathrm{C} .{ }^{1} \mathrm{H}$ NMR $\left(400 \mathrm{MHz}, \mathrm{CDCl}_{3}\right) \delta 8.73(\mathrm{~d}, J=1.0 \mathrm{~Hz}, 1 \mathrm{H}$, pyridine-H), 8.08 (d, $J=1.3 \mathrm{~Hz}, 1 \mathrm{H},-\mathrm{CO}-\mathrm{NH}), 8.05(\mathrm{~s}, 1 \mathrm{H}$, pyridine-H), 7.30-7.12 (m, 3H, Ar-H), $3.75\left(\mathrm{~s}, 2 \mathrm{H},-\mathrm{CH}_{2}\right), 3.67$ (q, $\left.J=6.4 \mathrm{~Hz}, 2 \mathrm{H},-\mathrm{CH}_{2}\right), 2.73\left(\mathrm{t}, J=6.5 \mathrm{~Hz}, 2 \mathrm{H},-\mathrm{CH}_{2}\right) .{ }^{13} \mathrm{C} \mathrm{NMR}$ $\left(100 \mathrm{MHz}, \mathrm{CDCl}_{3}\right) \delta 162.3,160.6(\mathrm{~d}, J=251.4 \mathrm{~Hz}), 149.0,142.9$ $(\mathrm{q}, J=3.7 \mathrm{~Hz}), 137.7(\mathrm{q}, J=3.6 \mathrm{~Hz}), 132.2,132.0(\mathrm{~d}, J=4.5 \mathrm{~Hz})$, $129.3(\mathrm{q}, J=34.0 \mathrm{~Hz}), 127.7(\mathrm{~d}, J=3.7 \mathrm{~Hz}), 124.7(\mathrm{~d}, J=14.9 \mathrm{~Hz})$, $122.2(\mathrm{~d}, J=273.4 \mathrm{~Hz}), 121.2(\mathrm{~d}, J=9.5 \mathrm{~Hz}), 119.2(\mathrm{~d}, J=25.1$
$\mathrm{Hz}$ ), 38.4, 31.2, 28.4 (d, $J=2.6 \mathrm{~Hz}) .{ }^{19} \mathrm{~F}$ NMR (376 $\mathrm{MHz}, \mathrm{CDCl}_{3}$ ) $\delta-62.52,-115.12$. HRMS: $[\mathrm{M}+\mathrm{H}]^{+}$calcd for $\mathrm{C}_{16} \mathrm{H}_{13} \mathrm{BrClF}_{4} \mathrm{~N}_{2}-$ OS: 470.95511 ; found: 470.95456 .

$\mathrm{N}$-(2-((2-Bromo-5-fluorobenzyl)thio)ethyl)-3-chloro-5-

(trifluoromethyl)picolinamide (E4). Yield 87\%; gray solid; mp 111-112 ${ }^{\circ} \mathrm{C} .{ }^{1} \mathrm{H}$ NMR (400 $\left.\mathrm{MHz}, \mathrm{CDCl}_{3}\right) \delta 8.77-8.68(\mathrm{~m}, 1 \mathrm{H}$, pyridine-H), 8.14-8.01 (m, 2H, pyridine-H, -CO-NH), 7.50 (dd, $J$ $=8.8,5.3 \mathrm{~Hz}, 1 \mathrm{H}, \mathrm{Ar}-\mathrm{H}), 7.20(\mathrm{dd}, J=9.1,3.0 \mathrm{~Hz}, 1 \mathrm{H}, \mathrm{Ar}-\mathrm{H})$, $6.85(\mathrm{td}, J=8.3,3.0 \mathrm{~Hz}, 1 \mathrm{H}, \mathrm{Ar}-\mathrm{H}), 3.87\left(\mathrm{~s}, 2 \mathrm{H},-\mathrm{CH}_{2}\right), 3.69(\mathrm{q}, J=$ $\left.6.4 \mathrm{~Hz}, 2 \mathrm{H},-\mathrm{CH}_{2}\right), 2.78\left(\mathrm{t}, J=6.5 \mathrm{~Hz}, 2 \mathrm{H},-\mathrm{CH}_{2}\right) .{ }^{13} \mathrm{C} \mathrm{NMR}(100$ $\left.\mathrm{MHz}, \mathrm{CDCl}_{3}\right) \delta 162.3,161.9(\mathrm{~d}, J=247.6 \mathrm{~Hz}), 149.0,142.9(\mathrm{q}, J=$ $3.8 \mathrm{~Hz}), 139.6(\mathrm{~d}, J=7.3 \mathrm{~Hz}), 137.7(\mathrm{q}, J=3.6 \mathrm{~Hz}), 134.2(\mathrm{~d}, J=$ $8.0 \mathrm{~Hz}), 132.2,129.3(\mathrm{q}, J=34.0 \mathrm{~Hz}), 122.2(\mathrm{~d}, J=273.4 \mathrm{~Hz})$, $118.5(\mathrm{~d}, J=3.3 \mathrm{~Hz}), 117.8(\mathrm{~d}, J=23.3 \mathrm{~Hz}), 116.1(\mathrm{~d}, J=22.4 \mathrm{~Hz})$, 38.5, 36.1, 31.4. ${ }^{19} \mathrm{~F}$ NMR (376 MHz, $\mathrm{CDCl}_{3}$ ) $\delta-62.52,-114.19$. HRMS: $[\mathrm{M}+\mathrm{H}]^{+}$calcd for $\mathrm{C}_{16} \mathrm{H}_{13} \mathrm{BrClF}_{4} \mathrm{~N}_{2} \mathrm{OS}$ : 470.95511; found: 470.95468.

3-Chloro-N-(2-((3-fluorobenzyl)thio)ethyl)-5-(trifluoromethyl) picolinamide (E5). Yield 66\%; yellow solid; mp $103-104{ }^{\circ} \mathrm{C} .{ }^{1} \mathrm{H}$ NMR (400 MHz, $\left.\mathrm{CDCl}_{3}\right) \delta 8.73(\mathrm{~d}, J=1.1 \mathrm{~Hz}, 1 \mathrm{H}$, pyridine-H), $8.08(\mathrm{~d}, J=1.3 \mathrm{~Hz}, 1 \mathrm{H}$, pyridine-H), $8.02(\mathrm{~s}, 1 \mathrm{H},-\mathrm{CO}-\mathrm{NH})$, 7.33-7.19 (m, 1H, Ar-H), 7.13-7.06 (m, 2H, Ar-H), $6.92(\mathrm{td}, J=$ 8.3, $2.0 \mathrm{~Hz}, 1 \mathrm{H}, \mathrm{Ar}-\mathrm{H}), 3.76\left(\mathrm{~s}, 2 \mathrm{H},-\mathrm{CH}_{2}\right), 3.63(\mathrm{q}, J=6.3 \mathrm{~Hz}, 2 \mathrm{H}$, $\left.-\mathrm{CH}_{2}\right), 2.71\left(\mathrm{t}, J=6.5 \mathrm{~Hz}, 2 \mathrm{H},-\mathrm{CH}_{2}\right) .{ }^{13} \mathrm{C} \mathrm{NMR}\left(100 \mathrm{MHz}, \mathrm{CDCl}_{3}\right)$ $\delta 162.9(\mathrm{~d}, J=246.4 \mathrm{~Hz}), 162.3,149.0,142.9(\mathrm{q}, J=3.8 \mathrm{~Hz}), 140.6$ $(\mathrm{d}, J=7.2 \mathrm{~Hz}), 137.7$ (q, $J=3.5 \mathrm{~Hz}), 132.2,130.1(\mathrm{~d}, J=8.3 \mathrm{~Hz})$, $129.3(\mathrm{q}, J=33.9 \mathrm{~Hz}), 124.6(\mathrm{~d}, J=2.8 \mathrm{~Hz}), 122.2(\mathrm{~d}, J=273.4$ $\mathrm{Hz}), 115.8$ (d, $J=21.7 \mathrm{~Hz}), 114.2$ (d, $J=21.1 \mathrm{~Hz}), 38.3,35.5$ (d, $J$ $=1.8 \mathrm{~Hz}$ ), 31.0. ${ }^{19} \mathrm{~F}$ NMR $\left(376 \mathrm{MHz}, \mathrm{CDCl}_{3}\right) \delta-62.52,-112.81$. HRMS: $[\mathrm{M}-\mathrm{H}]^{-}$calcd for $\mathrm{C}_{16} \mathrm{H}_{12} \mathrm{ClF}_{4} \mathrm{~N}_{2} \mathrm{OS}$ : 391.02895; found: 391.03027.

3-Chloro-N-(2-((2,3-dichlorobenzyl)thio)ethyl)-5-

(trifluoromethyl)picolinamide (E6). Yield 80\%; white solid; mp 130-132 ${ }^{\circ} \mathrm{C} .{ }^{1} \mathrm{H}$ NMR $\left(400 \mathrm{MHz}, \mathrm{CDCl}_{3}\right) \delta 8.73$ (dd, $J=1.8$, $0.7 \mathrm{~Hz}, 1 \mathrm{H}$, pyridine- $\mathrm{H}), 8.12-8.01(\mathrm{~m}, 2 \mathrm{H}$, pyridine- $\mathrm{H},-\mathrm{CO}-$ $\mathrm{NH}), 7.35(\mathrm{dd}, J=8.0,1.6 \mathrm{~Hz}, 1 \mathrm{H}, \mathrm{Ar}-\mathrm{H}), 7.31(\mathrm{dd}, J=7.7,1.6 \mathrm{~Hz}$, $1 \mathrm{H}, \mathrm{Ar}-\mathrm{H}), 7.16$ (t, J= $7.8 \mathrm{~Hz}, 1 \mathrm{H}, \mathrm{Ar}-\mathrm{H}), 3.92\left(\mathrm{~s}, 2 \mathrm{H},-\mathrm{CH}_{2}\right), 3.68$ $\left(\mathrm{q}, J=6.4 \mathrm{~Hz}, 2 \mathrm{H},-\mathrm{CH}_{2}\right), 2.77\left(\mathrm{t}, J=6.5 \mathrm{~Hz}, 2 \mathrm{H},-\mathrm{CH}_{2}\right) .{ }^{13} \mathrm{C} \mathrm{NMR}$ $\left(100 \mathrm{MHz}, \mathrm{CDCl}_{3}\right) \delta 162.3,149.0,142.9(\mathrm{q}, J=3.8 \mathrm{~Hz}), 138.2$, $137.7(\mathrm{q}, J=3.6 \mathrm{~Hz}), 133.6,132.4,132.2,129.4,129.3(\mathrm{q}, J=34.0$ $\mathrm{Hz}), 128.9,127.2,122.2(\mathrm{~d}, J=273.5 \mathrm{~Hz}), 38.6,34.5,31.4 .{ }^{19} \mathrm{~F}$ NMR (376 MHz, $\mathrm{CDCl}_{3}$ ) $\delta-62.51$. HRMS: $[\mathrm{M}+\mathrm{H}]^{+}$calcd for $\mathrm{C}_{16} \mathrm{H}_{13} \mathrm{Cl}_{3} \mathrm{~F}_{3} \mathrm{~N}_{2} \mathrm{OS}$ : 442.97608; found: 442.97546 .

3-Chloro-N-(2-((3-chloro-2-fluorobenzyl)thio)ethyl)-5-

(trifluoromethyl)picolinamide (E7). Yield 81\%; gray solid; mp 97$98{ }^{\circ} \mathrm{C} .{ }^{1} \mathrm{H} \mathrm{NMR}\left(400 \mathrm{MHz}, \mathrm{CDCl}_{3}\right) \delta 8.73(\mathrm{~d}, J=1.1 \mathrm{~Hz}, 1 \mathrm{H}$, pyridine-H), 8.07 (t, $J=3.1 \mathrm{~Hz}, 2 \mathrm{H}$, pyridine- $\mathrm{H},-\mathrm{CO}-\mathrm{NH}), 7.35-$ $7.16(\mathrm{~m}, 2 \mathrm{H}, \mathrm{Ar}-\mathrm{H}), 7.04(\mathrm{td}, J=7.9,1.1 \mathrm{~Hz}, 1 \mathrm{H}, \mathrm{Ar}-\mathrm{H}), 3.81$ (d, $\left.=0.8 \mathrm{~Hz}, 2 \mathrm{H},-\mathrm{CH}_{2}\right), 3.68\left(\mathrm{q}, J=6.4 \mathrm{~Hz}, 2 \mathrm{H},-\mathrm{CH}_{2}\right), 2.76(\mathrm{t}, J=$ $\left.6.5 \mathrm{~Hz}, 2 \mathrm{H},-\mathrm{CH}_{2}\right) .{ }^{13} \mathrm{C} \mathrm{NMR}\left(100 \mathrm{MHz}, \mathrm{CDCl}_{3}\right) \delta 162.3,157.5$, 149.0, 142.9 (q, $J=3.9 \mathrm{~Hz}), 137.7$ (q, $J=3.6 \mathrm{~Hz}), 132.2,129.6$, $129.3(\mathrm{q}, J=34.0 \mathrm{~Hz}), 129.2(\mathrm{~d}, J=3.3 \mathrm{~Hz}), 127.3(\mathrm{~d}, J=14.8 \mathrm{~Hz})$, 124.6 (d, $J=4.8 \mathrm{~Hz}), 122.2(\mathrm{q}, J=273.3 \mathrm{~Hz}), 121.3$ (d, $J=18.0$ $\mathrm{Hz}$ ), 38.4, 31.3, 29.0 (d, $J=2.8 \mathrm{~Hz}) .{ }^{19} \mathrm{~F} \mathrm{NMR} \mathrm{(376} \mathrm{MHz,} \mathrm{CDCl}_{3}$ ) $\delta-62.52,-119.81$. HRMS: $[\mathrm{M}-\mathrm{H}]^{-}$calcd for $\mathrm{C}_{16} \mathrm{H}_{11} \mathrm{Cl}_{2} \mathrm{~F}_{4} \mathrm{~N}_{2} \mathrm{OS}$ : 424.98998; found: 424.99158 . 
3-Chloro-N-(2-((3,4-difluorobenzyl)thio)ethyl)-5-

(trifluoromethyl)picolinamide (E8). Yield 68\%; white solid; mp 97-98 ${ }^{\circ} \mathrm{C} .{ }^{1} \mathrm{H}$ NMR $\left(400 \mathrm{MHz}, \mathrm{CDCl}_{3}\right) \delta 8.73$ (s, 1H, pyridine-H), $8.09(\mathrm{~s}, 1 \mathrm{H}$, pyridine-H), $8.02(\mathrm{~s}, 1 \mathrm{H},-\mathrm{CO}-\mathrm{NH}), 7.29-7.17(\mathrm{~m}, 1 \mathrm{H}$, $\mathrm{Ar}-\mathrm{H}$ ), 7.14-7.01 (m, 2H, Ar-H), 3.73 (s, 2H, $-\mathrm{CH}_{2}$ ), 3.67-3.58 (m, $\left.2 \mathrm{H},-\mathrm{CH}_{2}\right), 2.70\left(\mathrm{td}, J=6.5,1.6 \mathrm{~Hz}, 2 \mathrm{H},-\mathrm{CH}_{2}\right) .{ }^{13} \mathrm{C}$ NMR $(100$ $\mathrm{MHz} \mathrm{CDCl}_{3}$ ) $\delta 162.3,150.3(\mathrm{dd}, J=248.8,12.9 \mathrm{~Hz}$ ), $149.5(\mathrm{dd}, J$ $=247.9,12.7 \mathrm{~Hz}), 148.9,142.9(\mathrm{q}, J=3.7 \mathrm{~Hz}), 137.8(\mathrm{q}, J=3.6$ $\mathrm{Hz}$ ), 135.1 (dd, $J=5.2,4.1 \mathrm{~Hz}), 132.2,129.3(\mathrm{q}, J=33.9 \mathrm{~Hz})$, $124.8(\mathrm{dd}, J=6.2,3.6 \mathrm{~Hz}), 122.2(\mathrm{q}, J=273.5 \mathrm{~Hz}), 117.7(\mathrm{~d}, J=$ $17.4 \mathrm{~Hz}), 117.2(\mathrm{~d}, J=17.2 \mathrm{~Hz}), 38.3,35.1,30.9 .{ }^{19} \mathrm{~F}$ NMR $(376$ $\left.\mathrm{MHz}, \mathrm{CDCl}_{3}\right) \delta-62.54, \delta-137.19(\mathrm{~d}, J=21.2 \mathrm{~Hz}),-139.64(\mathrm{~d}, J$ $=21.2 \mathrm{~Hz})$. HRMS: $[\mathrm{M}-\mathrm{H}]^{-}$calcd for $\mathrm{C}_{16} \mathrm{H}_{11} \mathrm{ClF}_{5} \mathrm{~N}_{2} \mathrm{OS}$ : 409.01953; found: 409.02078 .

$\mathrm{N}$-(2-(Benzylthio)ethyl)-3-chloro-5-(trifluoromethyl)picolinamide (E9). Yield 75\%; brown solid; mp 109-110 ${ }^{\circ} \mathrm{C}$. ${ }^{1} \mathrm{H}$ NMR (400 $\left.\mathrm{MHz} \mathrm{CDCl}_{3}\right) \delta 8.73(\mathrm{~d}, J=1.0 \mathrm{~Hz}, 1 \mathrm{H}$, pyridine-H), 8.07 (d, $J=$ $1.3 \mathrm{~Hz}, 1 \mathrm{H}$, pyridine-H), $8.01(\mathrm{~s}, 1 \mathrm{H},-\mathrm{CO}-\mathrm{NH}), 7.36-7.27(\mathrm{~m}, 4 \mathrm{H}$, $\mathrm{Ar}-\mathrm{H}), 7.26-7.20(\mathrm{~m}, 1 \mathrm{H}, \mathrm{Ar}-\mathrm{H}), 3.78\left(\mathrm{~s}, 2 \mathrm{H},-\mathrm{CH}_{2}\right), 3.62$ (q, $J=$ $\left.6.3 \mathrm{~Hz}, 2 \mathrm{H},-\mathrm{CH}_{2}\right), 2.70\left(\mathrm{t}, J=6.5 \mathrm{~Hz}, 2 \mathrm{H},-\mathrm{CH}_{2}\right) .{ }^{13} \mathrm{C}$ NMR $(100$ $\left.\mathrm{MHz}, \mathrm{CDCl}_{3}\right) \delta 162.3,149.2,142.9(\mathrm{q}, J=3.8 \mathrm{~Hz}$ ), 138.0, 137.7 (q, $J=3.6 \mathrm{~Hz}$ ), 132.2, 129.2 (q, $J=34.1 \mathrm{~Hz}), 128.9,128.6,127.2$, $122.2(\mathrm{q}, J=273.5 \mathrm{~Hz}), 38.3,35.9,30.9 .{ }^{19} \mathrm{~F}$ NMR $(376 \mathrm{MHz}$, $\left.\mathrm{CDCl}_{3}\right) \delta-62.51$. HRMS: $[\mathrm{M}-\mathrm{H}]^{-}$calcd for $\mathrm{C}_{16} \mathrm{H}_{13} \mathrm{ClF}_{3} \mathrm{~N}_{2} \mathrm{OS}$ : 373.03955; found: 373.03837 .

3-Chloro-N-(2-(((3,4-dimethoxypyridin-2-yl)methyl)thio)ethyl)-5(trifluoromethyl)picolinamide (E10). Yield 60\%; gray solid; $\mathrm{mp}$ 76-77 ${ }^{\circ} \mathrm{C} .{ }^{1} \mathrm{H}$ NMR $\left(400 \mathrm{MHz}, \mathrm{CDCl}_{3}\right) \delta 8.72(\mathrm{~d}, J=1.0 \mathrm{~Hz}, 1 \mathrm{H}$, pyridine-H), 8.45 (s, $1 \mathrm{H}$, pyridine- $\mathrm{H}), 8.14(\mathrm{~d}, J=5.5 \mathrm{~Hz}, 1 \mathrm{H}$, pyridine-H), $8.06(\mathrm{~d}, J=1.3 \mathrm{~Hz}, 1 \mathrm{H},-\mathrm{CO}-\mathrm{NH}), 6.76(\mathrm{~d}, J=$ $5.6 \mathrm{~Hz}, 1 \mathrm{H}$, pyridine- $\mathrm{H}), 3.97-3.86\left(\mathrm{~m}, 8 \mathrm{H},-\left(\mathrm{OCH}_{3}\right)_{2},-\mathrm{CH}_{2}\right), 3.73$ (dd, $\left.J=12.3,6.0 \mathrm{~Hz}, 2 \mathrm{H},-\mathrm{CH}_{2}\right), 2.86\left(\mathrm{t}, J=6.2 \mathrm{~Hz}, 2 \mathrm{H},-\mathrm{CH}_{2}\right)$. ${ }^{13} \mathrm{C}$ NMR $\left(100 \mathrm{MHz}, \mathrm{CDCl}_{3}\right) \delta 162.5,158.8,152.7,150.0,145.4$, 143.4, 142.9 (q, $J=3.8 \mathrm{~Hz}), 137.3$ (q, $J=3.6 \mathrm{~Hz}), 131.9,129.0$ (q, $J$ $=33.9 \mathrm{~Hz}), 122.2(\mathrm{q}, J=273.4 \mathrm{~Hz}), 106.9,61.1,55.7,39.1,31.69$, 31.4. ${ }^{19} \mathrm{~F} \mathrm{NMR}\left(376 \mathrm{MHz}, \mathrm{CDCl}_{3}\right) \delta-62.50$. HRMS: $[\mathrm{M}+\mathrm{H}]^{+}$ calcd for $\mathrm{C}_{17} \mathrm{H}_{18} \mathrm{ClF}_{3} \mathrm{~N}_{3} \mathrm{O}_{3} \mathrm{~S}$ : 436.07040; found: 436.06998 .

3-Chloro-5-(trifluoromethyl)-N-(2-((4-(trifluoromethyl)benzyl)

thio)ethyl)picolinamide (E11). Yield 88\%; yellow solid; mp 114$115{ }^{\circ} \mathrm{C} .{ }^{1} \mathrm{H}$ NMR $\left(400 \mathrm{MHz}, \mathrm{CDCl}_{3}\right) \delta 8.75-8.70(\mathrm{~m}, 1 \mathrm{H}$, pyridine$\mathrm{H}), 8.12-8.06(\mathrm{~m}, 1 \mathrm{H}$, pyridine-H), 8.03 (s, 1H, -CO-NH), 7.57 (d, $J=8.1 \mathrm{~Hz}, 2 \mathrm{H}, \mathrm{Ar}-\mathrm{H}), 7.47(\mathrm{~d}, J=8.1 \mathrm{~Hz}, 2 \mathrm{H}), 3.82(\mathrm{~s}, 2 \mathrm{H}), 3.65$ $(\mathrm{q}, J=6.5 \mathrm{~Hz}, 2 \mathrm{H}), 2.69(\mathrm{t}, J=6.6 \mathrm{~Hz}, 2 \mathrm{H}) .{ }^{13} \mathrm{C} \mathrm{NMR}(100 \mathrm{MHz}$, $\left.\mathrm{CDCl}_{3}\right) \delta 162.3,148.9,142.9(\mathrm{q}, J=3.9 \mathrm{~Hz}), 142.2,137.8(\mathrm{q}, J=$ $3.6 \mathrm{~Hz}), 132.2,129.4$ (q, $J=32.6 \mathrm{~Hz}), 129.3$ (q, $J=34.0 \mathrm{~Hz}$ ), $129.2,125.6$ (q, $J=3.8 \mathrm{~Hz}), 124.1$ (q, $J=272.0 \mathrm{~Hz}), 122.1$ (q, $J=$ 273.4 Hz), 38.3, 35.4, 30.9. $\left.{ }^{19} \mathrm{~F} \mathrm{NMR} \mathrm{(376} \mathrm{MHz}, \mathrm{CDCl}_{3}\right) \delta-62.48$, -62.54. HRMS: $[\mathrm{M}+\mathrm{H}]^{+}$calcd for $\mathrm{C}_{17} \mathrm{H}_{14} \mathrm{ClF}_{6} \mathrm{~N}_{2} \mathrm{OS}$ : 443.04041; found: 443.04141.

3-Chloro-N-(2-((2-chloro-4-fluorobenzyl)thio)ethyl)-5-

(trifluoromethyl)picolinamide (E12). Yield 68\%; gray solid; $\mathrm{mp}$ 90-91 ${ }^{\circ} \mathrm{C} .{ }^{1} \mathrm{H}$ NMR $\left(400 \mathrm{MHz}, \mathrm{CDCl}_{3}\right) \delta 8.73(\mathrm{~s}, 1 \mathrm{H}), 8.08(\mathrm{~d}, J=$ $0.4 \mathrm{~Hz}, 2 \mathrm{H}), 7.38(\mathrm{dd}, J=8.5,6.1 \mathrm{~Hz}, 1 \mathrm{H}), 7.18-7.06(\mathrm{~m}, 1 \mathrm{H}), 6.95$ (ddd, $J=8.2,2.5,1.2 \mathrm{~Hz}, 1 \mathrm{H}), 3.86$ (s, 2H), 3.68 (q, $J=6.4 \mathrm{~Hz}$, 2H), 2.75 (t, $J=6.5 \mathrm{~Hz}, 2 \mathrm{H}) .{ }^{13} \mathrm{C} \mathrm{NMR}\left(100 \mathrm{MHz}, \mathrm{CDCl}_{3}\right) \delta 162.3$, $161.6(\mathrm{~d}, J=249.7 \mathrm{~Hz}), 149.0,142.9(\mathrm{q}, J=3.8 \mathrm{~Hz}), 137.7(\mathrm{q}, J=$
$3.5 \mathrm{~Hz}), 134.6(\mathrm{~d}, J=10.3 \mathrm{~Hz}), 132.2,131.8,131.7,129.3(\mathrm{q}, J=$ $34.0 \mathrm{~Hz}), 122.2(\mathrm{q}, J=273.4 \mathrm{~Hz}), 117.2(\mathrm{~d}, J=24.7 \mathrm{~Hz}), 114.2(\mathrm{~d}, J$ $=21.1 \mathrm{~Hz}), 38.6,32.8,31.2 .{ }^{19} \mathrm{~F} \mathrm{NMR}\left(376 \mathrm{MHz}, \mathrm{CDCl}_{3}\right.$ ) $\delta-62.52,-112.69$. HRMS: $[\mathrm{M}+\mathrm{H}]^{+}$calcd for $\mathrm{C}_{16} \mathrm{H}_{13} \mathrm{Cl}_{2} \mathrm{~F}_{4} \mathrm{~N}_{2} \mathrm{OS}$ : 427.00563; found: 427.00470 .

3-Chloro-N-(2-((4-isopropylbenzyl)thio)ethyl)-5-(trifluoromethyl) picolinamide (E13). Yield 79\%; yellow solid; mp 98-100 ${ }^{\circ} \mathrm{C} .{ }^{1} \mathrm{H}$ NMR (400 MHz, $\left.\mathrm{CDCl}_{3}\right) \delta 8.73(\mathrm{~d}, J=1.1 \mathrm{~Hz}, 1 \mathrm{H}), 8.11-8.06(\mathrm{~m}$, $1 \mathrm{H}), 8.03(\mathrm{~s}, 1 \mathrm{H}), 7.28-7.23(\mathrm{~m}, 2 \mathrm{H}), 7.17(\mathrm{~d}, J=8.1 \mathrm{~Hz}, 2 \mathrm{H}), 3.75$ (s, 2H), 3.64 (dd, $J=12.7,6.3 \mathrm{~Hz}, 2 \mathrm{H}), 2.88(\mathrm{dt}, J=13.9,6.9 \mathrm{~Hz}$, $1 \mathrm{H}), 2.70(\mathrm{t}, J=6.5 \mathrm{~Hz}, 2 \mathrm{H}), 1.23(\mathrm{~d}, J=6.9 \mathrm{~Hz}, 6 \mathrm{H}) .{ }^{13} \mathrm{C} \mathrm{NMR}$ $\left(100 \mathrm{MHz} \mathrm{CDCl}_{3}\right) \delta 162.2,149.2,147.9,142.8(\mathrm{q}, J=3.8 \mathrm{~Hz})$, $137.6(\mathrm{q}, J=3.5 \mathrm{~Hz}), 135.1,132.1,129.2(\mathrm{~d}, J=34.0 \mathrm{~Hz}), 128.8$, 126.7, 122.2 (q, $J=273.5 \mathrm{~Hz}$ ), 38.3, 35.5, 33.8, 30.8, 24.0. ${ }^{19} \mathrm{~F}$ NMR (376 MHz, $\mathrm{CDCl}_{3}$ ) $\delta-62.52$. HRMS: $[\mathrm{M}-\mathrm{H}]^{-}$calcd for $\mathrm{C}_{19} \mathrm{H}_{19} \mathrm{ClF}_{3} \mathrm{~N}_{2} \mathrm{OS}$ : 415.08532; found: 415.08630 .

$\mathrm{N}$-(2-((2-Bromo-4-fluorobenzyl)thio)ethyl)-3-chloro-5-

(trifluoromethyl)picolinamide (E14). Yield 64\%; yellow solid; mp 92-94 ${ }^{\circ} \mathrm{C} .{ }^{1} \mathrm{H}$ NMR $\left(400 \mathrm{MHz}, \mathrm{CDCl}_{3}\right) \delta 8.73(\mathrm{~d}, J=1.1 \mathrm{~Hz}, 1 \mathrm{H})$, 8.08 (d, $J=1.3 \mathrm{~Hz}, 1 \mathrm{H}), 8.05(\mathrm{~s}, 1 \mathrm{H}), 7.39$ (dd, $J=8.5,5.9 \mathrm{~Hz}$, $1 \mathrm{H}), 7.29(\mathrm{dd}, J=8.2,2.6 \mathrm{~Hz}, 1 \mathrm{H}), 6.99(\mathrm{td}, J=8.3,2.6 \mathrm{~Hz}, 1 \mathrm{H})$, $3.87(\mathrm{~s}, 2 \mathrm{H}), 3.68(\mathrm{q}, J=6.4 \mathrm{~Hz}, 2 \mathrm{H}), 2.76(\mathrm{t}, J=6.5 \mathrm{~Hz}, 2 \mathrm{H}) \cdot{ }^{13} \mathrm{C}$ NMR $\left(100 \mathrm{MHz}, \mathrm{CDCl}_{3}\right) \delta 162.3,161.4(\mathrm{~d}, J=250.8 \mathrm{~Hz}), 149.1$, $142.8(\mathrm{q}, J=3.8 \mathrm{~Hz}), 137.7(\mathrm{q}, J=3.6 \mathrm{~Hz}), 133.5(\mathrm{~d}, J=3.6 \mathrm{~Hz})$, 132.2, 131.7 (d, $J=8.4 \mathrm{~Hz}), 129.3(\mathrm{q}, J=34.0 \mathrm{~Hz}), 124.4(\mathrm{~d}, J=$ $9.6 \mathrm{~Hz}), 122.2(\mathrm{q}, J=273.4 \mathrm{~Hz}), 120.3(\mathrm{~d}, J=24.5 \mathrm{~Hz}), 114.8(\mathrm{~d}, J$ $=21.1 \mathrm{~Hz}), 38.6,35.5,31.3 .{ }^{19} \mathrm{~F} \mathrm{NMR}\left(376 \mathrm{MHz}, \mathrm{CDCl}_{3}\right)$ $\delta-62.55,-112.79$. HRMS: $[\mathrm{M}+\mathrm{H}]^{+}$calcd for $\mathrm{C}_{16} \mathrm{H}_{13} \mathrm{BrClF}_{4} \mathrm{~N}_{2}-$ OS: 470.95511 ; found: 470.95468 .

$\mathrm{N}$-(2-((3-Bromobenzyl)thio)ethyl)-3-chloro-5-(trifluoromethyl) picolinamide (E15). Yield 82\%; gray solid; mp 89-91 ${ }^{\circ} \mathrm{C} .{ }^{1} \mathrm{H} \mathrm{NMR}$ $\left(400 \mathrm{MHz}, \mathrm{CDCl}_{3}\right) \delta 8.74(\mathrm{~d}, J=1.0 \mathrm{~Hz}, 1 \mathrm{H}), 8.07$ (d, $J=1.4 \mathrm{~Hz}$, $1 \mathrm{H}), 8.01(\mathrm{~s}, 1 \mathrm{H}), 7.51(\mathrm{t}, J=1.6 \mathrm{~Hz}, 1 \mathrm{H}), 7.36(\mathrm{~d}, J=7.9 \mathrm{~Hz}, 1 \mathrm{H})$, $7.26(\mathrm{t}, J=3.8 \mathrm{~Hz}, 1 \mathrm{H}), 7.17(\mathrm{t}, J=7.8 \mathrm{~Hz}, 1 \mathrm{H}), 3.73(\mathrm{~s}, 2 \mathrm{H}), 3.63$ $(\mathrm{q}, J=6.3 \mathrm{~Hz}, 2 \mathrm{H}), 2.71(\mathrm{t}, J=6.5 \mathrm{~Hz}, 2 \mathrm{H}) .{ }^{13} \mathrm{C}$ NMR $(100 \mathrm{MHz}$, $\left.\mathrm{CDCl}_{3}\right) \delta 162.3,149.1,142.9(\mathrm{q}, J=3.8 \mathrm{~Hz}), 140.4,137.7(\mathrm{q}, J=$ $3.5 \mathrm{~Hz}), 132.2$, 131.9, 130.3, 130.1, 129.3 (q, $J=33.9 \mathrm{~Hz}), 127.5$, 122.7, 122.2 (q, $J=273.4 \mathrm{~Hz}), 38.4,35.5,31.1 .{ }^{19} \mathrm{~F}$ NMR (376 $\left.\mathrm{MHz}, \mathrm{CDCl}_{3}\right) \delta$-62.54. HRMS: $[\mathrm{M}+\mathrm{H}]^{+}$calcd for $\mathrm{C}_{16} \mathrm{H}_{14^{-}}$ $\mathrm{BrClF}_{3} \mathrm{~N}_{2} \mathrm{OS}$ : 452.96454; found: 452.96402 .

3-Chloro-N-(2-((2,6-difluorobenzyl)thio)ethyl)-5-

(trifluoromethyl)picolinamide (E16). Yield 72\%; white solid; mp 112-113 ${ }^{\circ} \mathrm{C} .{ }^{1} \mathrm{H}$ NMR (400 MHz, $\left.\mathrm{CDCl}_{3}\right) \delta 8.76-8.70(\mathrm{~m}, 1 \mathrm{H}), 8.07$ (dd, $J=1.2,0.6 \mathrm{~Hz}, 2 \mathrm{H}), 7.25-7.16(\mathrm{~m}, 1 \mathrm{H}), 6.93-6.85(\mathrm{~m}, 2 \mathrm{H})$, $3.82(\mathrm{~s}, 2 \mathrm{H}), 3.71(\mathrm{q}, J=6.2 \mathrm{~Hz}, 2 \mathrm{H}), 2.80(\mathrm{t}, J=6.4 \mathrm{~Hz}, 2 \mathrm{H}) \cdot{ }^{13} \mathrm{C}$ NMR (100 MHz, $\left.\mathrm{CDCl}_{3}\right) \delta 161.1$ (dd, $\left.J=248.7,7.9 \mathrm{~Hz}\right), 162.2$, 149.1, 142.9 (q, $J=3.8 \mathrm{~Hz}), 137.7$ (q, $J=3.4 \mathrm{~Hz}), 132.2,129.2$ (q, $J$ $=34.0 \mathrm{~Hz}), 128.8(\mathrm{t}, J=10.3 \mathrm{~Hz}), 122.2(\mathrm{q}, J=273.4 \mathrm{~Hz}), 115.0(\mathrm{t}$, $J=19.2 \mathrm{~Hz}), 111.4(\mathrm{q}, J=12.6 \mathrm{~Hz}), 38.3,31.6,22.3 .{ }^{19} \mathrm{~F} \mathrm{NMR}(376$ $\left.\mathrm{MHz}, \mathrm{CDCl}_{3}\right) \delta-62.52,-115.00$. HRMS: $[\mathrm{M}+\mathrm{H}]^{+}$calcd for $\mathrm{C}_{16} \mathrm{H}_{13} \mathrm{ClF}_{5} \mathrm{~N}_{2} \mathrm{OS}$ : 411.03518 ; found: 411.03448 .

3-Chloro-N-(2-((2-methylbenzyl)thio)ethyl)-5-(trifluoromethyl) picolinamide (E17). Yield 82\%; gray solid; mp 84-85 ${ }^{\circ} \mathrm{C} .{ }^{1} \mathrm{H} \mathrm{NMR}$ $\left(400 \mathrm{MHz}, \mathrm{CDCl}_{3}\right) \delta 8.72(\mathrm{~d}, J=1.0 \mathrm{~Hz}, 1 \mathrm{H}), 8.07(\mathrm{~d}, J=1.3 \mathrm{~Hz}$, $1 \mathrm{H}), 8.02(\mathrm{~s}, 1 \mathrm{H}), 7.25-7.19(\mathrm{~m}, 1 \mathrm{H}), 7.16-7.11(\mathrm{~m}, 3 \mathrm{H}), 3.78(\mathrm{~s}$, $2 \mathrm{H}), 3.65(\mathrm{q}, J=6.3 \mathrm{~Hz}, 2 \mathrm{H}), 2.74(\mathrm{t}, J=6.5 \mathrm{~Hz}, 2 \mathrm{H}), 2.41(\mathrm{~s}, 3 \mathrm{H})$. ${ }^{13} \mathrm{C} \mathrm{NMR}\left(100 \mathrm{MHz}, \mathrm{CDCl}_{3}\right) \delta 162.2,149.1,142.9(\mathrm{q}, J=3.9 \mathrm{~Hz})$, 
$137.7(\mathrm{q}, J=3.6 \mathrm{~Hz}), 136.7,135.6,132.2,130.9,129.7,129.2(\mathrm{~d}, J$ $=33.9 \mathrm{~Hz}), 127.5,126.0,122.2(\mathrm{~d}, J=273.3 \mathrm{~Hz}), 38.6,34.2,31.3$, 19.2. ${ }^{19} \mathrm{~F} \mathrm{NMR}\left(376 \mathrm{MHz}, \mathrm{CDCl}_{3}\right) \delta-62.50$. HRMS: $[\mathrm{M}+\mathrm{H}]^{+}$ calcd for $\mathrm{C}_{17} \mathrm{H}_{17} \mathrm{ClF}_{3} \mathrm{~N}_{2} \mathrm{OS}$ : 389.06967; found: 389.06924 .

3-Chloro-5-(trifluoromethyl)-N-(2-((2-(trifluoromethyl)benzyl) thio)ethyl)picolinamide (E18). Yield 60\%; yellow solid; mp 77$78{ }^{\circ} \mathrm{C} .{ }^{1} \mathrm{H}$ NMR $\left(400 \mathrm{MHz}, \mathrm{CDCl}_{3}\right) \delta 8.73(\mathrm{~d}, J=0.8 \mathrm{~Hz}, 1 \mathrm{H}), 8.08$ $(\mathrm{dd}, J=1.3,0.5 \mathrm{~Hz}, 2 \mathrm{H}), 7.64(\mathrm{t}, J=8.4 \mathrm{~Hz}, 2 \mathrm{H}), 7.52(\mathrm{t}, J=$ $7.5 \mathrm{~Hz}, 1 \mathrm{H}), 7.35$ (t, $J=7.6 \mathrm{~Hz}, 1 \mathrm{H}), 3.96(\mathrm{~s}, 2 \mathrm{H}), 3.66$ (q, $J=$ $6.4 \mathrm{~Hz}, 2 \mathrm{H}), 2.79(\mathrm{t}, J=6.5 \mathrm{~Hz}, 2 \mathrm{H}) .{ }^{13} \mathrm{C} \mathrm{NMR}\left(100 \mathrm{MHz}, \mathrm{CDCl}_{3}\right)$ $\delta 162.3,149.0,142.9$ (q, $J=3.8 \mathrm{~Hz}), 137.7$ (q, $J=3.6 \mathrm{~Hz}), 136.8$ $(\mathrm{d}, J=1.4 \mathrm{~Hz}), 132.2,132.1,131.5,129.3(\mathrm{q}, J=33.9 \mathrm{~Hz}), 128.5$ $(\mathrm{q}, J=29.9 \mathrm{~Hz}), 127.3,126.2(\mathrm{q}, J=5.6 \mathrm{~Hz}), 124.3(\mathrm{~d}, J=274.0$ $\mathrm{Hz}$ ), 122.2 (d, $J=273.5 \mathrm{~Hz}), 38.5,32.5$ (d, $J=2.0 \mathrm{~Hz}), 31.9 .{ }^{19} \mathrm{~F}$ NMR $\left(376 \mathrm{MHz}, \mathrm{CDCl}_{3}\right) \delta-59.05,-62.53$. HRMS: $[\mathrm{M}-\mathrm{H}]^{-}$ calcd for $\mathrm{C}_{17} \mathrm{H}_{12} \mathrm{ClF}_{6} \mathrm{~N}_{2} \mathrm{OS}$ : 441.02704 ; found: 441.02576 .

3-Chloro-N-(2-((2-chlorobenzyl)thio)ethyl)-5-(trifluoromethyl) picolinamide (E19). Yield 43\%; brown solid; $\mathrm{mp} 77-78{ }^{\circ} \mathrm{C} .{ }^{1} \mathrm{H}$ NMR (400 MHz, $\left.\mathrm{CDCl}_{3}\right) \delta 8.73(\mathrm{~d}, J=1.1 \mathrm{~Hz}, 1 \mathrm{H}), 8.07(\mathrm{~d}, J=$ $1.3 \mathrm{~Hz}, 2 \mathrm{H}), 7.39$ (dd, $J=7.3,1.9 \mathrm{~Hz}, 1 \mathrm{H}), 7.36(\mathrm{dd}, J=7.6$, $1.6 \mathrm{~Hz}, 1 \mathrm{H}), 7.25-7.16(\mathrm{~m}, 2 \mathrm{H}), 3.90(\mathrm{~s}, 2 \mathrm{H}), 3.68(\mathrm{q}, J=6.3 \mathrm{~Hz}$, $2 \mathrm{H}), 2.76(\mathrm{t}, J=6.5 \mathrm{~Hz}, 2 \mathrm{H}) .{ }^{13} \mathrm{C} \mathrm{NMR}\left(100 \mathrm{MHz}, \mathrm{CDCl}_{3}\right) \delta 162.3$, $149.1,142.9$ (q, $J=3.8 \mathrm{~Hz}), 137.7$ (q, $J=3.6 \mathrm{~Hz}), 135.8,134.0$, $132.2,130.9,129.9,129.2(\mathrm{q}, J=34.1 \mathrm{~Hz}), 128.7,127.0,122.2(\mathrm{q}, J$ $=273.5 \mathrm{~Hz}), 38.6,33.5,31.3 .{ }^{19} \mathrm{~F} \mathrm{NMR}\left(376 \mathrm{MHz}, \mathrm{CDCl}_{3}\right)$ $\delta$-62.51. HRMS: $[\mathrm{M}+\mathrm{H}]^{+}$calcd for $\mathrm{C}_{16} \mathrm{H}_{14} \mathrm{Cl}_{2} \mathrm{~F}_{3} \mathrm{~N}_{2} \mathrm{OS}$ : 409.01505; found: 409.01443.

N-(2-((4-(tert-Butyl)benzyl)thio)ethyl)-3-chloro-5-

(trifluoromethyl)picolinamide (E20). Yield 84\%; gray solid; mp 111-113 ${ }^{\circ} \mathrm{C} .{ }^{1} \mathrm{H}$ NMR $\left(400 \mathrm{MHz}, \mathrm{CDCl}_{3}\right) \delta 8.74(\mathrm{~d}, J=1.1 \mathrm{~Hz}, 1 \mathrm{H})$, $8.08(\mathrm{~d}, J=1.3 \mathrm{~Hz}, 1 \mathrm{H}), 8.04(\mathrm{~s}, 1 \mathrm{H}), 7.37-7.31(\mathrm{~m}, 2 \mathrm{H}), 7.30-7.18$ $(\mathrm{m}, 2 \mathrm{H}), 3.75(\mathrm{~s}, 2 \mathrm{H}), 3.64(\mathrm{q}, J=6.3 \mathrm{~Hz}, 2 \mathrm{H}), 2.70(\mathrm{t}, J=6.5 \mathrm{~Hz}$, $2 \mathrm{H}), 1.30(\mathrm{~s}, 9 \mathrm{H}) .{ }^{13} \mathrm{C} \mathrm{NMR}\left(100 \mathrm{MHz}, \mathrm{CDCl}_{3}\right) \delta 162.3,150.2$, $149.2,142.9$ (q, $J=3.8 \mathrm{~Hz}), 137.7$ (q, $J=3.5 \mathrm{~Hz}), 134.7,132.2$, $129.2(\mathrm{q}, J=33.9 \mathrm{~Hz}), 128.6,125.6,122.2(\mathrm{~d}, J=273.4 \mathrm{~Hz}), 38.3$, 35.4, 34.5, 31.3, 30.9. ${ }^{19} \mathrm{~F}$ NMR (376 MHz, $\mathrm{CDCl}_{3}$ ) $\delta-62.51$. HRMS: $[\mathrm{M}+\mathrm{H}]^{+}$calcd for $\mathrm{C}_{20} \mathrm{H}_{23} \mathrm{ClF}_{3} \mathrm{~N}_{2} \mathrm{OS}$ : 431.11662; found: 431.11563.

3-Chloro-N-(2-(((6-chloropyridin-3-yl)methyl)thio)ethyl)-5-

(trifluoromethyl)picolinamide (E21). Yield 48\%; brown solid; $\mathrm{mp}$ 88-89 ${ }^{\circ} \mathrm{C} .{ }^{1} \mathrm{H}$ NMR $\left(400 \mathrm{MHz}, \mathrm{CDCl}_{3}\right) \delta 8.73(\mathrm{~s}, 1 \mathrm{H}), 8.34(\mathrm{~d}, J=$ $2.2 \mathrm{~Hz}, 1 \mathrm{H}), 8.09(\mathrm{~s}, 1 \mathrm{H}), 8.05(\mathrm{~s}, 1 \mathrm{H}), 7.70(\mathrm{dd}, J=8.2,2.4 \mathrm{~Hz}$, $1 \mathrm{H}), 7.29(\mathrm{~d}, J=8.2 \mathrm{~Hz}, 1 \mathrm{H}), 3.76(\mathrm{~s}, 2 \mathrm{H}), 3.66(\mathrm{q}, J=6.5 \mathrm{~Hz}, 2 \mathrm{H})$, $2.70(\mathrm{t}, J=6.6 \mathrm{~Hz}, 2 \mathrm{H}) .{ }^{13} \mathrm{C}$ NMR $\left(100 \mathrm{MHz}, \mathrm{CDCl}_{3}\right) \delta 162.4$, 150.3, 149.7, 148.8, 142.9 (q, $J=3.8 \mathrm{~Hz}), 139.3,137.8$ (q, $J=3.6$ $\mathrm{Hz}), 132.9,132.3,129.4(\mathrm{q}, J=34.0 \mathrm{~Hz}), 124.3,122.1(\mathrm{q}, J=273.4$ $\mathrm{Hz}$ ), 38.4, 32.3, 31.0. ${ }^{19} \mathrm{~F}$ NMR (376 MHz, $\left.\mathrm{CDCl}_{3}\right) \delta-62.52$. HRMS: $[\mathrm{M}-\mathrm{H}]^{-}$calcd for $\mathrm{C}_{15} \mathrm{H}_{11} \mathrm{Cl}_{2} \mathrm{~F}_{3} \mathrm{~N}_{3} \mathrm{OS}$ : 407.99465; found: 407.99591.

3-Chloro-N-(2-((4-cyanobenzyl)thio)ethyl)-5-(trifluoromethyl) picolinamide (E22). Yield $83 \%$; gray solid; mp $87-89{ }^{\circ} \mathrm{C} .{ }^{1} \mathrm{H} \mathrm{NMR}$ $\left(400 \mathrm{MHz}, \mathrm{CDCl}_{3}\right) \delta 8.73(\mathrm{~d}, J=1.0 \mathrm{~Hz}, 1 \mathrm{H}), 8.12-8.07(\mathrm{~m}, 1 \mathrm{H})$, $8.03(\mathrm{~s}, 1 \mathrm{H}), 7.61(\mathrm{~d}, J=8.1 \mathrm{~Hz}, 2 \mathrm{H}), 7.47(\mathrm{~d}, J=8.2 \mathrm{~Hz}, 2 \mathrm{H}), 3.81$ $(\mathrm{s}, 2 \mathrm{H}), 3.64(\mathrm{q}, J=6.5 \mathrm{~Hz}, 2 \mathrm{H}), 2.68(\mathrm{t}, J=6.7 \mathrm{~Hz}, 2 \mathrm{H}) .{ }^{13} \mathrm{C} \mathrm{NMR}$ $\left(100 \mathrm{MHz}, \mathrm{CDCl}_{3}\right) \delta 162.3,148.9,143.7,142.9(\mathrm{q}, J=3.8 \mathrm{~Hz})$, $137.8(\mathrm{q}, J=3.6 \mathrm{~Hz}), 132.4,132.3,129.7,129.4(\mathrm{q}, J=33.3 \mathrm{~Hz})$, $122.1(\mathrm{~d}, J=273.4 \mathrm{~Hz}), 118.7,111.1,38.4,35.6,31.0 .{ }^{19} \mathrm{~F}$ NMR
(376 $\mathrm{MHz}, \mathrm{CDCl}_{3}$ ) $\delta$-62.51. HRMS: $[\mathrm{M}-\mathrm{H}]^{-}$calcd for $\mathrm{C}_{17^{-}}$ $\mathrm{H}_{12} \mathrm{ClF}_{3} \mathrm{~N}_{3} \mathrm{OS}$ : 398.03362; found: 398.03470.

3-Chloro-N-(2-((3,5-difluorobenzyl)thio)ethyl)-5-

(trifluoromethyl)picolinamide (E23). Yield 83\%; white solid; mp 94-95 ${ }^{\circ} \mathrm{C} .{ }^{1} \mathrm{H}$ NMR $\left(400 \mathrm{MHz}, \mathrm{CDCl}_{3}\right) \delta 8.74(\mathrm{~d}, J=1.1 \mathrm{~Hz}, 1 \mathrm{H})$, 8.13-8.07 (m, 1H), $8.03(\mathrm{~s}, 1 \mathrm{H}), 6.99-6.82(\mathrm{~m}, 2 \mathrm{H}), 6.68(\mathrm{tt}, J=$ $8.9,2.3 \mathrm{~Hz}, 1 \mathrm{H}), 3.74(\mathrm{~s}, 2 \mathrm{H}), 3.64(\mathrm{q}, J=6.4 \mathrm{~Hz}, 2 \mathrm{H}), 2.72(\mathrm{t}, J=$ $6.5 \mathrm{~Hz}, 2 \mathrm{H}) .{ }^{13} \mathrm{C}$ NMR $\left(100 \mathrm{MHz}, \mathrm{CDCl}_{3}\right) \delta 163.0(\mathrm{dd}, J=249.0$, $12.8 \mathrm{~Hz}), 162.3,148.9,142.9(\mathrm{q}, J=3.8 \mathrm{~Hz}), 142.1(\mathrm{t}, J=9.0 \mathrm{~Hz})$, $137.8(\mathrm{q}, J=3.6 \mathrm{~Hz}), 132.3,129.3(\mathrm{q}, J=33.9 \mathrm{~Hz}), 122.2(\mathrm{q}, J=$ $273.5 \mathrm{~Hz}), 111.8$ (q, $J=11.7 \mathrm{~Hz}), 102.8(\mathrm{t}, J=25.3 \mathrm{~Hz}), 38.3,35.5$, 31.1. ${ }^{19} \mathrm{~F} \mathrm{NMR}\left(376 \mathrm{MHz}, \mathrm{CDCl}_{3}\right) \delta-62.53,-109.51$. HRMS: [M $-\mathrm{H}]^{-}$calcd for $\mathrm{C}_{16} \mathrm{H}_{11} \mathrm{ClF}_{5} \mathrm{~N}_{2} \mathrm{OS}$ : 409.01953; found: 409.02075 .

3-Chloro-N-(2-(((3-methyl-4-(trifluoromethoxy)pyridin-2-yl) methyl)thio)ethyl)-5-(trifluoromethyl)picolinamide (E24). Yield 77\%; gray solid; mp $124-125{ }^{\circ} \mathrm{C} .{ }^{1} \mathrm{H}$ NMR (400 MHz, $\mathrm{CDCl}_{3}$ ) $\delta 8.72(\mathrm{~s}, 1 \mathrm{H}), 8.40(\mathrm{~s}, 1 \mathrm{H}), 8.27(\mathrm{~d}, J=5.7 \mathrm{~Hz}, 1 \mathrm{H}), 8.06(\mathrm{~d}, J=$ $1.1 \mathrm{~Hz}, 1 \mathrm{H}), 6.63(\mathrm{~d}, J=5.7 \mathrm{~Hz}, 1 \mathrm{H}), 4.39$ (q, $J=7.9 \mathrm{~Hz}, 2 \mathrm{H}), 3.93$ (s, $2 \mathrm{H}), 3.70(\mathrm{dd}, J=12.4,6.0 \mathrm{~Hz}, 2 \mathrm{H}), 2.82(\mathrm{t}, J=6.3 \mathrm{~Hz}, 2 \mathrm{H})$, 2.29 (s, 3H). ${ }^{13} \mathrm{C}$ NMR (100 MHz, $\left.\mathrm{CDCl}_{3}\right) \delta$ 162.5, 161.8, 158.1, 149.8, 147.5, 142.9 (q, $J=3.8 \mathrm{~Hz}), 137.4$ (q, $J=3.7 \mathrm{~Hz}), 131.9$, $129.0(\mathrm{q}, J=33.8 \mathrm{~Hz}), 123.0(\mathrm{q}, J=277.8 \mathrm{~Hz}), 122.2(\mathrm{q}, J=273.3$ $\mathrm{Hz}), 121.1,105.4,65.4(\mathrm{q}, J=36.3 \mathrm{~Hz}), 39.2,35.4,31.1,10.6 .{ }^{19} \mathrm{~F}$ NMR (376 MHz, $\left.\mathrm{CDCl}_{3}\right) \delta-62.53,-73.85$. HRMS: $[\mathrm{M}+\mathrm{H}]^{+}$calcd for $\mathrm{C}_{18} \mathrm{H}_{17} \mathrm{ClF}_{6} \mathrm{~N}_{3} \mathrm{O}_{2} \mathrm{~S}$ : 488.06287; found: 488.06143 .

3-Chloro-N-(2-((3,4,4-trifluorobut-3-en-1-yl)thio)ethyl)-5-

(trifluoromethyl)picolinamide (E25). Yield 84\%; brown solid; mp 69-70 ${ }^{\circ} \mathrm{C} .{ }^{1} \mathrm{H}$ NMR $\left(400 \mathrm{MHz}, \mathrm{CDCl}_{3}\right) \delta 8.74(\mathrm{~d}, J=1.0 \mathrm{~Hz}, 1 \mathrm{H})$, $8.11(\mathrm{~s}, 1 \mathrm{H}), 8.08(\mathrm{~d}, J=1.4 \mathrm{~Hz}, 1 \mathrm{H}), 3.68(\mathrm{q}, J=6.5 \mathrm{~Hz}, 2 \mathrm{H}), 2.83$ $(\mathrm{t}, J=5.4 \mathrm{~Hz}, 2 \mathrm{H}), 2.79(\mathrm{t}, J=6.0 \mathrm{~Hz}, 2 \mathrm{H}), 2.60$ (dddd, $J=11.1$, 7.1, 5.3, 3.2 Hz, 2H). ${ }^{13} \mathrm{C}$ NMR (100 MHz, $\left.\mathrm{CDCl}_{3}\right) \delta 162.3,153.6$ (ddd, $J=287.1,273.3,46.3 \mathrm{~Hz}), 148.9,142.9$ (q, $J=3.8 \mathrm{~Hz}$ ), $137.7(\mathrm{q}, J=3.6 \mathrm{~Hz}), 132.2,129.3(\mathrm{q}, J=34.0 \mathrm{~Hz}), 127.2$ (ddd, $J=$ 69.7, 56.0, 16.2 Hz), 122.2 (q, $J=273.4 \mathrm{~Hz}), 38.7,31.6,27.6,26.4$ $(\mathrm{dd}, J=21.9,2.6 \mathrm{~Hz}) .{ }^{19} \mathrm{~F}$ NMR $\left(376 \mathrm{MHz}, \mathrm{CDCl}_{3}\right) \delta-62.55$, $-103.74(\mathrm{dd}, J=85.2,32.5 \mathrm{~Hz}),-123.06(\mathrm{dd}, J=114.4,85.2 \mathrm{~Hz})$, -175.59 (dd, $J=114.2,32.4 \mathrm{~Hz}$ ). HRMS: $[\mathrm{M}+\mathrm{H}]^{+}$calcd for $\mathrm{C}_{12} \mathrm{H}_{8} \mathrm{ClF}_{4} \mathrm{~N}_{2} \mathrm{OS}$ : 393.04372; found: 393.04463.

3-Chloro-N-(2-((2,5-difluorobenzyl)thio)ethyl)-5-

(trifluoromethyl)picolinamide (E26). Yield 62\%; white solid; mp 111-112 ${ }^{\circ} \mathrm{C} .{ }^{1} \mathrm{H}$ NMR $\left(400 \mathrm{MHz}, \mathrm{CDCl}_{3}\right) \delta 8.74(\mathrm{~d}, J=1.1 \mathrm{~Hz}, 1 \mathrm{H})$, $8.08(\mathrm{~d}, J=1.3 \mathrm{~Hz}, 1 \mathrm{H}), 7.12(\mathrm{ddd}, J=8.8,5.8,3.1 \mathrm{~Hz}, 1 \mathrm{H}), 7.00$ $(\mathrm{td}, J=9.0,4.5 \mathrm{~Hz}, 1 \mathrm{H}), 6.94-6.86(\mathrm{~m}, 1 \mathrm{H}), 3.77(\mathrm{~s}, 2 \mathrm{H}), 3.67$ (q, $=6.3 \mathrm{~Hz}, 2 \mathrm{H}), 2.76(\mathrm{t}, J=6.5 \mathrm{~Hz}, 2 \mathrm{H}) .{ }^{13} \mathrm{C}$ NMR $(100 \mathrm{MHz}$, $\left.\mathrm{CDCl}_{3}\right) \delta 162.3,158.6(\mathrm{dd}, J=242.8,2.4 \mathrm{~Hz}), 156.8(\mathrm{dd}, J=242.2$, $2.5 \mathrm{~Hz}), 149.0,142.9$ (q, $J=3.8 \mathrm{~Hz}), 137.7$ (q, $J=3.6 \mathrm{~Hz}), 132.2$, $129.3(\mathrm{q}, J=34.0 \mathrm{~Hz}), 127.1(\mathrm{dd}, J=17.4,7.6 \mathrm{~Hz}), 122.2(\mathrm{q}, J=$ $273.3 \mathrm{~Hz}$ ), 117.2 (dd, $J=24.4,4.1 \mathrm{~Hz}), 116.6(\mathrm{dd}, J=24.9,8.7$ $\mathrm{Hz}), 115.4$ (dd, $J=22.8,7.3 \mathrm{~Hz}), 38.3,31.3,28.6 .{ }^{19} \mathrm{~F}$ NMR (376 $\left.\mathrm{MHz}, \mathrm{CDCl}_{3}\right) \delta-62.53, \delta-118.44(\mathrm{~d}, J=17.8 \mathrm{~Hz}),-124.24(\mathrm{~d}, J$ $=17.8 \mathrm{~Hz})$. HRMS: $[\mathrm{M}-\mathrm{H}]^{-}$calcd for $\mathrm{C}_{16} \mathrm{H}_{11} \mathrm{ClF}_{5} \mathrm{~N}_{2} \mathrm{OS}$ : 409.01953; found: 409.02078 .

4.2.3 The synthesis of sulfone-containing compounds F1F10. Taking F1 as an example, to a mixture of 3-chloro- $N-(2-((4-$ fluorobenzyl)thio)ethyl)-5-(trifluoromethyl)picolinamide (E1, $1.27 \mathrm{mmol}$ ) and $20 \mathrm{~mL}$ EtOH stirred at room temperature, $\mathrm{H}_{2} \mathrm{O}_{2}$ $(53.46 \mathrm{mmol})$ and ammonium molybdate $(0.089 \mathrm{mmol})$ were 
added. The resulting solution was stirred at $100{ }^{\circ} \mathrm{C}$ and monitored by TLC. After about 7-8 h, the reaction could be completed. The solvent was removed under reduced pressure to provide crude product, which was purified by silica gel (200-300 mesh) column chromatography with ethyl acetate/petroleum ether $(1: 3)$ to obtain pure sulfone-containing compound F1. The sulfone-containing compounds F2-F10 could be also synthesized with similar method. The data of F1-F10 are listed below, and the spectra are shown in ESI data. $\dagger$

3-Chloro-N-(2-((4-fluorobenzyl)sulfonyl)ethyl)-5-

(trifluoromethyl)picolinamide (F1). Yield 41\%; white solid; $\mathrm{mp}$ $132-133{ }^{\circ} \mathrm{C} .{ }^{1} \mathrm{H}$ NMR $\left(400 \mathrm{MHz}, \mathrm{CDCl}_{3}\right) \delta 8.72(\mathrm{~d}, J=1.1 \mathrm{~Hz}, 1 \mathrm{H}$, pyridine-H), $8.40(\mathrm{t}, J=5.3 \mathrm{~Hz}, 1 \mathrm{H},-\mathrm{CO}-\mathrm{NH}-), 8.07(\mathrm{~d}, J=$ $1.4 \mathrm{~Hz}, 1 \mathrm{H}$, pyridine- $\mathrm{H}), 7.33-7.23(\mathrm{~m}, 2 \mathrm{H}, \mathrm{Ar}-\mathrm{H}), 7.15-7.00(\mathrm{~m}$, $2 \mathrm{H}, \mathrm{Ar}-\mathrm{H}$ ), 4.03 (q, $\left.J=13.2 \mathrm{~Hz}, 2 \mathrm{H},-\mathrm{CH}_{2}-\right), 3.96(\mathrm{dd}, J=12.1$, $\left.6.1 \mathrm{~Hz}, 2 \mathrm{H},-\mathrm{CH}_{2}-\right), 3.11-2.77\left(\mathrm{~m}, 2 \mathrm{H},-\mathrm{CH}_{2}-\right) .{ }^{13} \mathrm{C}$ NMR (100 $\left.\mathrm{MHz} \mathrm{CDCl}_{3}\right) \delta 162.9(\mathrm{~d}, J=248.2 \mathrm{~Hz}), 162.8,148.7,143.0(\mathrm{q}, J=$ $3.8 \mathrm{~Hz}), 137.6$ (q, $J=3.6 \mathrm{~Hz}), 132.1,131.9(\mathrm{~d}, J=8.3 \mathrm{~Hz}), 129.4$ $(\mathrm{q}, J=34.1 \mathrm{~Hz}), 125.2(\mathrm{~d}, J=3.3 \mathrm{~Hz}), 122.1(\mathrm{q}, J=273.3 \mathrm{~Hz})$, $116.1(\mathrm{~d}, J=21.7 \mathrm{~Hz}), 57.4,49.5,34.4 .{ }^{19} \mathrm{~F}$ NMR $(376 \mathrm{MHz}$, $\left.\mathrm{CDCl}_{3}\right) \delta-62.57,-112.80$. HRMS: calculated for $\mathrm{C}_{16} \mathrm{H}_{14} \mathrm{O}_{3} \mathrm{~N}_{2}$ $\mathrm{ClF}_{4} \mathrm{~S}[\mathrm{M}+\mathrm{H}]^{+}:$435.03443; found: 425.03378 .

3-Chloro-N-(2-((2-fluoro-5-(trifluoromethyl)benzyl)sulfonyl) ethyl)-5-(trifluoromethyl)picolinamide (F2). Yield 50\%; white solid; mp 150-151 ${ }^{\circ} \mathrm{C} .{ }^{1} \mathrm{H}$ NMR $\left(400 \mathrm{MHz}, \mathrm{CDCl}_{3}\right) \delta 8.73(\mathrm{~d}, J=$ $0.9 \mathrm{~Hz}, 1 \mathrm{H}$, pyridine-H), 8.37 (s, 1H, -CO-NH-), 8.07 (d, $J=$ $1.4 \mathrm{~Hz}, 1 \mathrm{H}$, pyridine-H), 7.71-7.60 (m, 2H, Ar-H), $7.26(\mathrm{dd}, J=$ 11.5, $6.1 \mathrm{~Hz}, 1 \mathrm{H}, \mathrm{Ar}-\mathrm{H}), 4.14$ (dd, $J=38.7,13.2 \mathrm{~Hz}, 2 \mathrm{H},-\mathrm{CH}_{2}-$ ), $3.99\left(\mathrm{q}, J=6.1 \mathrm{~Hz}, 2 \mathrm{H},-\mathrm{CH}_{2}-\right), 3.33-2.55\left(\mathrm{~m}, 2 \mathrm{H},-\mathrm{CH}_{2}-\right) .{ }^{13} \mathrm{C}$ NMR (100 MHz, $\left.\mathrm{CDCl}_{3}\right) \delta 162.8,162.8(\mathrm{~d}, J=253.8 \mathrm{~Hz}), 148.6$, 143.0 (q, $J=3.8 \mathrm{~Hz}), 137.7$ (q, $J=3.6 \mathrm{~Hz}), 132.2,129.9$ (q, $J=8.0$ $\mathrm{Hz}), 129.4(\mathrm{q}, J=34.1 \mathrm{~Hz}), 128.0(\mathrm{~d}, J=9.4 \mathrm{~Hz}), 127.4(\mathrm{q}, J=33.4$ $\mathrm{Hz}), 123.4(\mathrm{q}, J=272.2 \mathrm{~Hz}), 122.1(\mathrm{~d}, J=273.5 \mathrm{~Hz}), 118.3(\mathrm{~d}, J=$ $16.4 \mathrm{~Hz}), 116.5(\mathrm{~d}, J=23.2 \mathrm{~Hz}), 50.8,50.3,34.3 .{ }^{19} \mathrm{~F} \mathrm{NMR}(376$ $\left.\mathrm{MHz}, \mathrm{CDCl}_{3}\right) \delta-62.03,-62.60,-110.62$. HRMS: calculated for $\mathrm{C}_{16} \mathrm{H}_{14} \mathrm{O}_{3} \mathrm{~N}_{2} \mathrm{ClF}_{4} \mathrm{~S}[\mathrm{M}+\mathrm{H}]^{+}: 477.02690$; found: 477.02563 .

$\mathrm{N}$-(2-((4-Bromo-2-fluorobenzyl)sulfonyl)ethyl)-3-chloro-5-

(trifluoromethyl)picolinamide (F3). Yield 47\%; yellow solid; $\mathrm{mp}$ $124-125{ }^{\circ} \mathrm{C} .{ }^{1} \mathrm{H}$ NMR $\left(400 \mathrm{MHz}, \mathrm{CDCl}_{3}\right) \delta 8.72(\mathrm{~d}, J=1.0 \mathrm{~Hz}, 1 \mathrm{H}$, pyridine-H), $8.38(\mathrm{t}, J=5.2 \mathrm{~Hz}, 1 \mathrm{H},-\mathrm{CO}-\mathrm{NH}-), 8.07(\mathrm{~d}, J=$ $1.2 \mathrm{~Hz}, 1 \mathrm{H}$, pyridine-H), $7.32(\mathrm{~d}, J=8.8 \mathrm{~Hz}, 2 \mathrm{H}, \mathrm{Ar}-\mathrm{H}), 7.25$ (dd, $J$ $=14.0,6.0 \mathrm{~Hz}, 1 \mathrm{H}, \mathrm{Ar}-\mathrm{H}), 4.06\left(\mathrm{dd}, J=36.8,13.4 \mathrm{~Hz}, 2 \mathrm{H},-\mathrm{CH}_{2}-\right.$ ), $3.96\left(\mathrm{dt}, J=7.1,3.4 \mathrm{~Hz}, 2 \mathrm{H},-\mathrm{CH}_{2}-\right)$, 3.15-2.79 (m, $\left.2 \mathrm{H},-\mathrm{CH}_{2}-\right)$. ${ }^{13} \mathrm{C}$ NMR $\left(100 \mathrm{MHz}, \mathrm{CDCl}_{3}\right) \delta 162.8,160.7(\mathrm{~d}, J=252.3 \mathrm{~Hz})$, 148.7, $143.0(\mathrm{q}, J=3.8 \mathrm{~Hz}), 137.6(\mathrm{q}, J=3.5 \mathrm{~Hz}), 133.4(\mathrm{~d}, J=3.9$ $\mathrm{Hz}), 132.1,129.4(\mathrm{q}, J=34.1 \mathrm{~Hz}), 128.1(\mathrm{~d}, J=3.7 \mathrm{~Hz}), 123.2$, $122.1(\mathrm{q}, J=273.5 \mathrm{~Hz}), 119.5(\mathrm{~d}, J=24.9 \mathrm{~Hz}), 116.0(\mathrm{~d}, J=15.3$ $\mathrm{Hz}$ ), 50.6, 50.0, 34.4. ${ }^{19} \mathrm{~F}$ NMR $\left(376 \mathrm{MHz}, \mathrm{CDCl}_{3}\right) \delta-62.57$, -113.50. HRMS: calculated for $\mathrm{C}_{16} \mathrm{H}_{13} \mathrm{O}_{3} \mathrm{~N}_{2} \mathrm{BrClF}_{4} \mathrm{~S}[\mathrm{M}+\mathrm{H}]^{+}$: 502.94494; found: 502.94443 .

$\mathrm{N}-(2-((2-B r o m o-5-f l u o r o b e n z y l)$ sulfonyl $)$ ethyl $)-3-c h l o r o-5-$

(trifluoromethyl)picolinamide (F4). Yield 44\%; white solid; mp $146-147{ }^{\circ} \mathrm{C} .{ }^{1} \mathrm{H}$ NMR $\left(400 \mathrm{MHz}, \mathrm{CDCl}_{3}\right) \delta 8.73(\mathrm{~d}, J=1.1 \mathrm{~Hz}, 1 \mathrm{H}$, pyridine-H), $8.41(\mathrm{t}, J=5.3 \mathrm{~Hz}, 1 \mathrm{H},-\mathrm{CO}-\mathrm{NH}-), 8.07$ (d, $J=$ $1.3 \mathrm{~Hz}, 1 \mathrm{H}$, pyridine-H), 7.58 (dd, $J=8.8,5.2 \mathrm{~Hz}, 1 \mathrm{H}, \mathrm{Ar}-\mathrm{H}), 7.17$ $(\mathrm{dd}, J=8.7,3.0 \mathrm{~Hz}, 1 \mathrm{H}, \mathrm{Ar}-\mathrm{H}), 6.97$ (ddd, $J=8.8,7.9,3.0 \mathrm{~Hz}, 1 \mathrm{H}$, $\mathrm{Ar}-\mathrm{H}), 4.22$ (dd, $\left.J=48.0,13.0 \mathrm{~Hz}, 2 \mathrm{H},-\mathrm{CH}_{2}-\right)$, 4.05-3.95 (m, $2 \mathrm{H}$,
$-\mathrm{CH}_{2}-$ ), 3.25-2.90 (m, 2H, $\left.-\mathrm{CH}_{2}-\right) .{ }^{13} \mathrm{C} \mathrm{NMR} \mathrm{(100} \mathrm{MHz,} \mathrm{CDCl}_{3}$ ) $\delta 162.8,161.7(\mathrm{~d}, J=249.1 \mathrm{~Hz}), 148.8,143.1(\mathrm{q}, J=3.8 \mathrm{~Hz}), 137.6$ $(\mathrm{q}, J=3.6 \mathrm{~Hz}) 134.5(\mathrm{~d}, J=8.1 \mathrm{~Hz}), 132.1,131.8(\mathrm{~d}, J=8.0 \mathrm{~Hz})$, 129.4 (q, $J=34.0 \mathrm{~Hz}), 122.1(\mathrm{q}, J=273.4 \mathrm{~Hz}), 119.5(\mathrm{~d}, J=23.5$ $\mathrm{Hz}), 119.2(\mathrm{~d}, J=3.5 \mathrm{~Hz}), 117.6(\mathrm{~d}, J=22.4 \mathrm{~Hz}), 58.3,50.1,34.5$. ${ }^{19} \mathrm{~F}$ NMR $\left(376 \mathrm{MHz}, \mathrm{CDCl}_{3}\right) \delta-62.57,-113.05$. HRMS: calculated for $\mathrm{C}_{16} \mathrm{H}_{13} \mathrm{O}_{3} \mathrm{~N}_{2} \mathrm{BrClF}_{4} \mathrm{~S}[\mathrm{M}+\mathrm{H}]^{+}$: 502.94494; found: 502.94223.

3-Chloro-N-(2-((3-fluorobenzyl)sulfonyl)ethyl)-5-

(trifluoromethyl)picolinamide (F5). Yield 50\%; yellow solid; mp 97-98 ${ }^{\circ} \mathrm{C} .{ }^{1} \mathrm{H}$ NMR $\left(400 \mathrm{MHz}, \mathrm{CDCl}_{3}\right) \delta 8.73(\mathrm{~d}, J=1.1 \mathrm{~Hz}, 1 \mathrm{H}$, pyridine-H), $8.41(\mathrm{t}, J=5.3 \mathrm{~Hz}, 1 \mathrm{H},-\mathrm{CO}-\mathrm{NH}-), 8.07(\mathrm{~d}, J=$ $1.3 \mathrm{~Hz}, 1 \mathrm{H}$, pyridine-H), 7.41-7.30 (m, 1H, Ar-H), 7.16-6.94 (m, $3 \mathrm{H}, \mathrm{Ar}-\mathrm{H}), 4.10-4.00\left(\mathrm{~m}, 2 \mathrm{H},-\mathrm{CH}_{2}-\right), 4.00-3.93\left(\mathrm{~m}, 2 \mathrm{H},-\mathrm{CH}_{2}-\right)$, 3.13-2.79 (m, 2H, $\left.-\mathrm{CH}_{2}-\right) .{ }^{13} \mathrm{C}$ NMR $\left(100 \mathrm{MHz}, \mathrm{CDCl}_{3}\right) \delta 162.9$ (d, $J=247.8 \mathrm{~Hz}), 162.8,148.8,143.1(\mathrm{q}, J=3.8 \mathrm{~Hz}), 137.6(\mathrm{q}, J=3.6$ $\mathrm{Hz}), 132.1,131.7$ (d, $J=7.7 \mathrm{~Hz}), 130.6$ (d, $J=8.3 \mathrm{~Hz}), 129.4(\mathrm{q}, J$ $=34.0 \mathrm{~Hz}), 125.9(\mathrm{~d}, J=3.0 \mathrm{~Hz}), 122.1(\mathrm{q}, J=273.4 \mathrm{~Hz}), 117.1(\mathrm{~d}$, $J=22.0 \mathrm{~Hz}), 115.7(\mathrm{~d}, J=21.0 \mathrm{~Hz}), 57.8,49.7,34.4 .{ }^{19} \mathrm{~F} \mathrm{NMR}(376$ $\left.\mathrm{MHz}, \mathrm{CDCl}_{3}\right) \delta-62.57,-111.70$. HRMS: calculated for $\mathrm{C}_{16} \mathrm{H}_{14}{ }^{-}$ $\mathrm{O}_{3} \mathrm{~N}_{2} \mathrm{ClF}_{4} \mathrm{~S}[\mathrm{M}+\mathrm{H}]^{+}$: 425.03443; found: 425.03293 .

3-Chloro-N-(2-((2,3-dichlorobenzyl)sulfonyl)ethyl)-5-

(trifluoromethyl)picolinamide (F6). Yield 44\%; faint yellow solid; mp 161-162 ${ }^{\circ} \mathrm{C} .{ }^{1} \mathrm{H}$ NMR $\left(400 \mathrm{MHz}, \mathrm{CDCl}_{3}\right) \delta 8.73(\mathrm{~d}, J=1.1 \mathrm{~Hz}$, $1 \mathrm{H}$, pyridine-H), $8.41(\mathrm{t}, J=5.5 \mathrm{~Hz}, 1 \mathrm{H},-\mathrm{CO}-\mathrm{NH}-), 8.07(\mathrm{~d}, J=$ $1.3 \mathrm{~Hz}, 1 \mathrm{H}$, pyridine-H), 7.48 (dd, $J=8.0,1.6 \mathrm{~Hz}, 1 \mathrm{H}, \mathrm{Ar}-\mathrm{H}), 7.32$ (dd, $J=7.7,1.6 \mathrm{~Hz}, 1 \mathrm{H}, \mathrm{Ar}-\mathrm{H}), 7.23$ (t, $J=7.8 \mathrm{~Hz}, 1 \mathrm{H}, \mathrm{Ar}-\mathrm{H}), 4.27$ $\left(\mathrm{dd}, J=39.0,12.9 \mathrm{~Hz}, 2 \mathrm{H},-\mathrm{CH}_{2}-\right), 4.01(\mathrm{dd}, J=12.1,6.1 \mathrm{~Hz}, 2 \mathrm{H}$, $-\mathrm{CH}_{2}-$ ), 3.23-2.89 (m, 2H, $\left.-\mathrm{CH}_{2}-\right)$. ${ }^{13} \mathrm{C} \mathrm{NMR} \mathrm{(100} \mathrm{MHz,} \mathrm{CDCl}_{3}$ ) $\delta 162.8,148.7,143.1(\mathrm{q}, J=3.8 \mathrm{~Hz}), 137.6(\mathrm{q}, J=3.6 \mathrm{~Hz}), 134.0$, 133.0, 132.1, 130.9, 130.6, 130.3, 129.4 (q, $J=34.0 \mathrm{~Hz}), 127.7$, 122.1 (q, $J=273.5 \mathrm{~Hz}), 57.0,50.2,34.4 .{ }^{19} \mathrm{~F}$ NMR $(376 \mathrm{MHz}$, $\left.\mathrm{CDCl}_{3}\right) \delta-62.56$. HRMS: calculated for $\mathrm{C}_{16} \mathrm{H}_{13} \mathrm{O}_{3} \mathrm{~N}_{2} \mathrm{Cl}_{3} \mathrm{~F}_{4} \mathrm{~S}[\mathrm{M}+$ $\mathrm{H}]^{+}$: 474.96591; found: 474.96579 .

3-Chloro-N-(2-((3-chloro-2-fluorobenzyl)sulfonyl)ethyl)-5-

(trifluoromethyl)picolinamide (F7). Yield 40\%; pale yellow solid; mp 145-146 ${ }^{\circ} \mathrm{C} .{ }^{1} \mathrm{H}$ NMR $\left(400 \mathrm{MHz}, \mathrm{CDCl}_{3}\right) \delta 8.73(\mathrm{~d}, J=1.1 \mathrm{~Hz}$, $1 \mathrm{H}), 8.39$ (t, $J=5.5 \mathrm{~Hz}, 1 \mathrm{H}), 8.07$ (d, $J=1.3 \mathrm{~Hz}, 1 \mathrm{H}), 7.45-7.36$ (m, 1H), 7.30-7.24 (m, 1H), $7.12(\mathrm{td}, J=7.9,1.0 \mathrm{~Hz}, 1 \mathrm{H}), 4.13$ (ddd, $J=30.9,13.2,1.1 \mathrm{~Hz}, 2 \mathrm{H}), 4.02-3.94$ (m, 2H), 3.19-2.83 $(\mathrm{m}, 2 \mathrm{H}) .{ }^{19} \mathrm{~F}$ NMR $\left(376 \mathrm{MHz}, \mathrm{CDCl}_{3}\right) \delta-62.56,-117.99 .{ }^{13} \mathrm{C}$ NMR (100 MHz, $\mathrm{CDCl}_{3}$ ) $\delta$ 162.8, 156.5 (d, $\left.J=249.8 \mathrm{~Hz}\right), 148.7$, $143.0(\mathrm{q}, J=3.9 \mathrm{~Hz}), 137.6(\mathrm{q}, J=3.5 \mathrm{~Hz}), 132.1,131.2,130.6(\mathrm{~d}, J$ $=2.7 \mathrm{~Hz}), 129.4(\mathrm{q}, J=34.0 \mathrm{~Hz}), 125.1(\mathrm{~d}, J=4.8 \mathrm{~Hz}), 122.1(\mathrm{q}, J$ $=273.4 \mathrm{~Hz}), 121.7(\mathrm{~d}, J=17.9 \mathrm{~Hz}), 118.7(\mathrm{~d}, J=15.2 \mathrm{~Hz}), 51.2$, 50.1, 34.4. HRMS: calculated for $\mathrm{C}_{16} \mathrm{H}_{13} \mathrm{O}_{3} \mathrm{~N}_{2} \mathrm{Cl}_{2} \mathrm{~F}_{4} \mathrm{~S}[\mathrm{M}+\mathrm{H}]^{+}$: 458.99546; found: 458.99557.

3-Chloro-N-(2-((3,4-difluorobenzyl)sulfonyl)ethyl)-5-

(trifluoromethyl)picolinamide (F8). Yield 84\%; white solid; mp 163-164 ${ }^{\circ} \mathrm{C} .{ }^{1} \mathrm{H}$ NMR $\left(400 \mathrm{MHz}, \mathrm{CDCl}_{3}\right) \delta 8.74(\mathrm{~d}, J=1.1 \mathrm{~Hz}, 1 \mathrm{H}$, pyridine-H), $8.32(\mathrm{t}, J=5.5 \mathrm{~Hz}, 1 \mathrm{H},-\mathrm{CO}-\mathrm{NH}-), 8.09(\mathrm{~d}, J=$ $1.3 \mathrm{~Hz}, 1 \mathrm{H}$, pyridine- $\mathrm{H}), 7.35-7.27(\mathrm{~m}, 1 \mathrm{H}, \mathrm{Ar}-\mathrm{H}), 7.25-7.11(\mathrm{~m}$, $2 \mathrm{H}, \mathrm{Ar}-\mathrm{H}), 4.26\left(\mathrm{~s}, 2 \mathrm{H},-\mathrm{CH}_{2}-\right), 3.96(\mathrm{dd}, J=12.2,6.2 \mathrm{~Hz}, 2 \mathrm{H}$, $-\mathrm{CH}_{2}-$ ), 3.44-3.07 (m, 2H, $\left.-\mathrm{CH}_{2}-\right)$. ${ }^{13} \mathrm{C} \mathrm{NMR} \mathrm{(100} \mathrm{MHz,} \mathrm{CDCl}_{3}$ ) $\delta 162.6,151.1(\mathrm{dd}, J=248.7,9.4 \mathrm{~Hz}), 150.5(\mathrm{dd}, J=257.0,19.3$ $\mathrm{Hz}), 148.2,143.1$ (q, $J=3.8 \mathrm{~Hz}), 137.8$ (q, $J=3.5 \mathrm{~Hz}), 132.3$, $129.6(\mathrm{q}, J=34.1 \mathrm{~Hz}), 127.1(\mathrm{dd}, J=6.6,3.8 \mathrm{~Hz}), 124.0(\mathrm{dd}, J=$ 
6.1, $4.1 \mathrm{~Hz}), 122.1$ (d, $J=273.5 \mathrm{~Hz}), 120.0(\mathrm{~d}, J=18.0 \mathrm{~Hz}), 118.1$ $(\mathrm{d}, J=17.5 \mathrm{~Hz}), 59.4,50.8,33.1 .{ }^{19} \mathrm{~F} \mathrm{NMR}\left(376 \mathrm{MHz}, \mathrm{CDCl}_{3}\right.$ ) $\delta-62.59,-135.47\left(\mathrm{~d},{ }^{3} J_{\mathrm{F}-\mathrm{F}}=21.2 \mathrm{~Hz}\right),-135.85\left(\mathrm{~d},{ }^{3} J_{\mathrm{F}-\mathrm{F}}=21.2\right.$ $\mathrm{Hz}$ ). HRMS: calculated for $\mathrm{C}_{16} \mathrm{H}_{13} \mathrm{O}_{3} \mathrm{~N}_{3} \mathrm{ClF}_{5} \mathrm{~S}[\mathrm{M}+\mathrm{H}]^{+}$: 443.02501; found: 443.02417 .

$\mathrm{N}$-(2-(Benzylsulfonyl)ethyl)-3-chloro-5-(trifluoromethyl) picolinamide (F9). Yield 39\%; soil white solid; mp 137-138 ${ }^{\circ} \mathrm{C}$. ${ }^{1} \mathrm{H}$ NMR $\left(400 \mathrm{MHz}, \mathrm{CDCl}_{3}\right) \delta 8.72(\mathrm{~d}, J=1.1 \mathrm{~Hz}, 1 \mathrm{H}$, pyridine-H), $8.41(\mathrm{t}, J=4.8 \mathrm{~Hz}, 1 \mathrm{H},-\mathrm{CO}-\mathrm{NH}-), 8.06$ (d, $J=1.3 \mathrm{~Hz}, 1 \mathrm{H}$, pyridine-H), 7.41-7.33 (m, 3H, Ar-H), $7.30(\mathrm{dt}, J=5.3,4.3 \mathrm{~Hz}$, $2 \mathrm{H}, \mathrm{Ar}-\mathrm{H}), 4.13-4.03\left(\mathrm{~m}, 2 \mathrm{H},-\mathrm{CH}_{2}-\right), 3.96$ (hd, $J=9.2,6.1 \mathrm{~Hz}$, $\left.2 \mathrm{H},-\mathrm{CH}_{2}-\right)$, 3.08-2.76 (m, 2H, $\left.-\mathrm{CH}_{2}-\right) .{ }^{13} \mathrm{C}$ NMR $(100 \mathrm{MHz}$, $\left.\mathrm{CDCl}_{3}\right) \delta 162.7,148.9,143.1(\mathrm{q}, J=3.8 \mathrm{~Hz}), 137.6(\mathrm{q}, J=3.6 \mathrm{~Hz})$, $132.1,130.1,129.4(\mathrm{q}, J=23.9 \mathrm{~Hz}), 129.3,129.1,128.6,122.1(\mathrm{q}, J$ $=273.4 \mathrm{~Hz}), 58.5,49.3$, 34.4. ${ }^{19} \mathrm{~F} \mathrm{NMR}\left(376 \mathrm{MHz}, \mathrm{CDCl}_{3}\right)$ $\delta-62.56$. HRMS: calculated for $\mathrm{C}_{16} \mathrm{H}_{15} \mathrm{O}_{3} \mathrm{~N}_{2} \mathrm{ClF}_{3} \mathrm{~S}[\mathrm{M}+\mathrm{H}]^{+}$: 407.04385; found: 407.04343 .

3-Chloro-N-(2-(((3,4-dimethoxypyridin-2-yl)methyl)sulfonyl) ethyl)-5-(trifluoromethyl)picolinamide (F10). Yield 35\%; pale yellow solid; mp $113-114{ }^{\circ} \mathrm{C} .{ }^{1} \mathrm{H}$ NMR $\left(400 \mathrm{MHz} \mathrm{CDCl}_{3}\right) \delta 8.72$ $(\mathrm{d}, J=1.0 \mathrm{~Hz}, 1 \mathrm{H}$, pyridine-H), $8.63(\mathrm{t}, J=5.2 \mathrm{~Hz}, 1 \mathrm{H},-\mathrm{CO}-\mathrm{NH}-$ ), $8.21(\mathrm{~d}, J=5.5 \mathrm{~Hz}, 1 \mathrm{H}$, pyridine $-\mathrm{H}), 8.05(\mathrm{~d}, J=1.3 \mathrm{~Hz}, 1 \mathrm{H}$, pyridine- $\mathrm{H}), 6.82(\mathrm{~d}, J=5.5 \mathrm{~Hz}, 1 \mathrm{H}$, pyridine- $\mathrm{H}), 4.37$ (dd, $J=$ 63.7, $12.4 \mathrm{~Hz}, 2 \mathrm{H},-\mathrm{CH}_{2}-$ ), 4.03 (dt, $J=8.4,3.9 \mathrm{~Hz}, 2 \mathrm{H},-\mathrm{CH}_{2}-$ ), $3.92\left(\mathrm{~d}, J=3.4 \mathrm{~Hz}, 6 \mathrm{H},-\mathrm{CH}_{3}\right), 3.28-3.04\left(\mathrm{~m}, 2 \mathrm{H},-\mathrm{CH}_{2}-\right) .{ }^{13} \mathrm{C}$ NMR $\left(100 \mathrm{MHz}, \mathrm{CDCl}_{3}\right) \delta 162.69,158.83,149.33,146.07,145.09$, 144.29, 143.01 (q, $J=3.8 \mathrm{~Hz}), 137.40$ (q, $J=3.5 \mathrm{~Hz}), 131.90$, $129.13(\mathrm{q}, J=34.0 \mathrm{~Hz}), 122.16(\mathrm{q}, J=273.4 \mathrm{~Hz}), 107.74,61.50$, 55.79, 54.66, 49.85, 34.33. $\left.{ }^{19} \mathrm{~F} \mathrm{NMR} \mathrm{(376} \mathrm{MHz,} \mathrm{CDCl}_{3}\right) \delta-62.56$. HRMS: calculated for $\mathrm{C}_{17} \mathrm{H}_{18} \mathrm{O}_{5} \mathrm{~N}_{3} \mathrm{ClF}_{3} \mathrm{~S}[\mathrm{M}+\mathrm{H}]^{+}$: 468.06023; found: 468.06030 .

4.2.4 The synthesis of sulfoxide-containing compounds G1-G16. According to the reported method, ${ }^{\mathbf{1 4}}$ sulfoxidecontaining compounds G1-G16 were also synthesized via the oxidation of thioether-containing compounds E11-E26. For G1 as an example, compound E11 (1.27 mmol) were treated with a mixture of $\mathrm{H}_{2} \mathrm{O}_{2}(26.73 \mathrm{mmol})$ and $\mathrm{Na}_{2} \mathrm{WO}_{4} \cdot 2 \mathrm{H}_{2} \mathrm{O}(0.089$ $\mathrm{mmol})$. The resulting mixture was stirred at room temperature for about $24 \mathrm{~h}$. After the completion of the reaction, solvent was removed under reduced pressure to provide crude product, which was purified by silica gel (200-300 mesh) column chromatography with ethyl acetate/petroleum ether $(1: 3)$. Other sulfoxide-containing compounds G2-G16 could be also synthesized with the similar method. The confirming data are listed below, and the spectra are listed in ESI data. $\dagger$

3-Chloro-5-(trifluoromethyl)-N-(2-((4-(trifluoromethyl)benzyl) sulfinyl)ethyl)picolinamide (G1). Yield 54\%; white solid; mp 184$185{ }^{\circ} \mathrm{C} .{ }^{1} \mathrm{H}$ NMR $\left(400 \mathrm{MHz}, \mathrm{CDCl}_{3}\right) \delta 8.72$ (s, $1 \mathrm{H}$, pyridine-H), 8.37 (br, 1H, -CO-NH-), 8.07 (s, 1H, pyridine-H), 7.65 (d, $J=$ $8.0 \mathrm{~Hz}, 2 \mathrm{H}, \mathrm{Ar}-\mathrm{H}), 7.45$ (d, $J=7.9 \mathrm{~Hz}, 2 \mathrm{H}, \mathrm{Ar}-\mathrm{H}), 4.10$ (dd, $J=$ $\left.37.2,13.0 \mathrm{~Hz}, 2 \mathrm{H},-\mathrm{CH}_{2}-\right), 3.96\left(\mathrm{dt}, J=10.8,5.6 \mathrm{~Hz}, 2 \mathrm{H},-\mathrm{CH}_{2}-\right.$ ), $3.0\left(\mathrm{dtd}, J=18.8,12.8,5.9 \mathrm{~Hz}, 2 \mathrm{H},-\mathrm{CH}_{2}-\right) .{ }^{13} \mathrm{C} \mathrm{NMR}(100 \mathrm{MHz}$, $\left.\mathrm{CDCl}_{3}\right) \delta 162.83,148.61,143.03(\mathrm{q}, J=3.8 \mathrm{~Hz}), 137.7(\mathrm{q}, J=3.6$ $\mathrm{Hz}), 133.5,132.2,130.8$ (q, $J=32.7 \mathrm{~Hz}), 130.6,129.5(\mathrm{q}, J=34.0$ $\mathrm{Hz}), 126.0$ (q, $J=3.7 \mathrm{~Hz}), 123.9$ (q, $J=272.3 \mathrm{~Hz}), 122.1$ (q, $J=$ $273.5 \mathrm{~Hz}), 57.6,50.0,34.4 .{ }^{19} \mathrm{~F} \mathrm{NMR}\left(376 \mathrm{MHz}, \mathrm{CDCl}_{3}\right) \delta-62.59$,
-62.76. HRMS: calculated for $\mathrm{C}_{17} \mathrm{H}_{14} \mathrm{O}_{2} \mathrm{~N}_{2} \mathrm{ClF}_{6} \mathrm{~S}[\mathrm{M}+\mathrm{H}]^{+}$: 459.03632; found: 459.03659 .

3-Chloro-N-(2-((2-chloro-4-fluorobenzyl)sulfinyl)ethyl)-5-

(trifluoromethyl)picolinamide (G2). Yield $60 \%$; soil white solid; mp 165-166 ${ }^{\circ} \mathrm{C} .{ }^{1} \mathrm{H}$ NMR $\left(400 \mathrm{MHz}, \mathrm{CDCl}_{3}\right) \delta 8.73(\mathrm{~d}, J=1.1 \mathrm{~Hz}$, $1 \mathrm{H}$, pyridine-H), $8.38(\mathrm{t}, J=5.2 \mathrm{~Hz}, 1 \mathrm{H},-\mathrm{CO}-\mathrm{NH}-), 8.12-8.02$ (m, $1 \mathrm{H}$, pyridine- $\mathrm{H}), 7.46-7.37(\mathrm{~m}, 1 \mathrm{H}, \mathrm{Ar}-\mathrm{H}), 7.32-7.23(\mathrm{~m}, 1 \mathrm{H}$, $\mathrm{Ar}-\mathrm{H}), 7.12(\mathrm{td}, J=8.0,0.8 \mathrm{~Hz}, 1 \mathrm{H}, \mathrm{Ar}-\mathrm{H}), 4.14$ (dt, $J=29.9$, $\left.7.1 \mathrm{~Hz}, 2 \mathrm{H},-\mathrm{CH}_{2}-\right), 3.99\left(\mathrm{q}, J=6.1 \mathrm{~Hz}, 2 \mathrm{H},-\mathrm{CH}_{2}-\right.$ ), 2.98 (ddt, $J=$ 13.2, 11.1, $\left.6.1 \mathrm{~Hz}, 2 \mathrm{H},-\mathrm{CH}_{2}-\right) .{ }^{13} \mathrm{C} \mathrm{NMR} \mathrm{(100} \mathrm{MHz,} \mathrm{CDCl}_{3}$ ) $\delta 162.8,156.5(\mathrm{~d}, J=249.8 \mathrm{~Hz}), 148.7,143.0(\mathrm{q}, J=3.8 \mathrm{~Hz}), 137.6$ $(\mathrm{q}, J=3.5 \mathrm{~Hz}), 132.1,131.2,130.6(\mathrm{~d}, J=2.8 \mathrm{~Hz}), 129.4(\mathrm{q}, J=$ $34.1 \mathrm{~Hz}), 125.0(\mathrm{~d}, J=4.8 \mathrm{~Hz}), 122.1(\mathrm{q}, J=273.5 \mathrm{~Hz}), 121.8(\mathrm{~d}, J$ $=18.0 \mathrm{~Hz}), 118.7$ (d, $J=15.2 \mathrm{~Hz}), 51.3,50.2,34.4 .{ }^{19} \mathrm{~F} \mathrm{NMR}(376$ $\left.\mathrm{MHz}, \mathrm{CDCl}_{3}\right) \delta-62.58,-117.98$. HRMS: calculated for $\mathrm{C}_{16} \mathrm{H}_{13^{-}}$ $\mathrm{O}_{2} \mathrm{~N}_{2} \mathrm{Cl}_{2} \mathrm{~F}_{4} \mathrm{~S}[\mathrm{M}+\mathrm{H}]^{+}$: 443.00054; found: 442.99860 .

3-Chloro-N-(2-((4-isopropylbenzyl)sulfinyl)ethyl)-5-

(trifluoromethyl)picolinamide (G3). Yield 45\%; faint yellow solid; mp 180-181 ${ }^{\circ} \mathrm{C} .{ }^{1} \mathrm{H}$ NMR $\left(400 \mathrm{MHz}, \mathrm{CDCl}_{3}\right) \delta 8.73(\mathrm{~d}, J=1.1 \mathrm{~Hz}$, $1 \mathrm{H}$, pyridine-H), $8.44(\mathrm{t}, J=5.4 \mathrm{~Hz}, 1 \mathrm{H},-\mathrm{CO}-\mathrm{NH}-), 8.06(\mathrm{~d}, J=$ $1.4 \mathrm{~Hz}, 1 \mathrm{H}$, pyridine-H), 7.26-7.19 (m, 4H, Ar-H), 4.05 (q, $J=$ $\left.13.0 \mathrm{~Hz}, 2 \mathrm{H},-\mathrm{CH}_{2}-\right)$, 4.00-3.92 (m, $\left.2 \mathrm{H},-\mathrm{CH}_{2}-\right)$, 3.02 (ddd, $J=$ 13.1, 7.4, $5.5 \mathrm{~Hz}, 1 \mathrm{H},-\mathrm{CH}-)$, 2.93-2.78 (m, 2H, $\left.-\mathrm{CH}_{2}-\right), 1.24(\mathrm{~d}, J$ $\left.=6.9 \mathrm{~Hz}, 6 \mathrm{H},-\mathrm{CH}_{3}\right) .{ }^{13} \mathrm{C} \mathrm{NMR}\left(100 \mathrm{MHz}, \mathrm{CDCl}_{3}\right) \delta 162.7,149.5$, 149.0, 143.1 (q, $J=3.8 \mathrm{~Hz}$ ), 137.6 (q, $J=3.6 \mathrm{~Hz}$ ), 132.0, 130.1, $129.3(\mathrm{q}, J=34.0 \mathrm{~Hz}), 127.2,126.4,122.1(\mathrm{q}, J=273.5 \mathrm{~Hz}), 58.2$, 49.2, 34.5, 33.9, 23.9. ${ }^{19} \mathrm{~F}$ NMR (376 $\left.\mathrm{MHz}, \mathrm{CDCl}_{3}\right) \delta-62.56$. HRMS: calculated for $\mathrm{C}_{19} \mathrm{H}_{21} \mathrm{O}_{2} \mathrm{~N}_{2} \mathrm{ClF}_{3} \mathrm{~S}[\mathrm{M}+\mathrm{H}]^{+}$: 433.09589; found: 433. 09573.

$\mathrm{N}$-(2-((2-Bromo-4-fluorobenzyl)sulfinyl)ethyl)-3-chloro-5-

(trifluoromethyl)picolinamide (G4). Yield 38\%; faint yellow solid; mp 184-185 ${ }^{\circ} \mathrm{C} .{ }^{1} \mathrm{H}$ NMR $\left(400 \mathrm{MHz}, \mathrm{CDCl}_{3}\right) \delta 8.73(\mathrm{~d}, J=1.1 \mathrm{~Hz}$, $1 \mathrm{H}$, pyridine-H), $8.38(\mathrm{t}, J=5.1 \mathrm{~Hz}, 1 \mathrm{H},-\mathrm{CO}-\mathrm{NH}-), 8.07(\mathrm{~d}, J=$ $1.4 \mathrm{~Hz}, 1 \mathrm{H}$, pyridine-H), 7.39 (ddd, $J=8.1,7.5,4.2 \mathrm{~Hz}, 2 \mathrm{H}, \mathrm{Ar}-$ H), 7.11-6.99 (m, 1H, Ar-H), $4.22(\mathrm{dd}, J=46.5,13.1 \mathrm{~Hz}, 2 \mathrm{H}$, $-\mathrm{CH}_{2}-$ ), 4.01 (ddd, $J=8.0,5.5,1.4 \mathrm{~Hz}, 2 \mathrm{H},-\mathrm{CH}_{2}-$ ), 3.25-2.84 (m, $\left.2 \mathrm{H},-\mathrm{CH}_{2}-\right) .{ }^{13} \mathrm{C}$ NMR $\left(100 \mathrm{MHz}, \mathrm{CDCl}_{3}\right) \delta 162.8,162.4(\mathrm{~d}, J=$ $253.3 \mathrm{~Hz}), 148.8,143.1(\mathrm{q}, J=3.9 \mathrm{~Hz}), 137.62(\mathrm{q}, J=3.6 \mathrm{~Hz})$, $133.5(\mathrm{~d}, J=8.6 \mathrm{~Hz}), 132.1,129.4(\mathrm{q}, J=34.1 \mathrm{~Hz}), 125.8(\mathrm{~d}, J=$ $3.7 \mathrm{~Hz}), 125.2(\mathrm{~d}, J=9.7 \mathrm{~Hz}), 122.1(\mathrm{q}, J=273.4 \mathrm{~Hz}), 120.7(\mathrm{~d}, J=$ $24.7 \mathrm{~Hz}), 115.3$ (d, $J=21.2 \mathrm{~Hz}), 57.7,49.9,34.5 .{ }^{19} \mathrm{~F}$ NMR (376 $\left.\mathrm{MHz}, \mathrm{CDCl}_{3}\right) \delta-62.58,-110.16$. HRMS: calculated for $\mathrm{C}_{16} \mathrm{H}_{13^{-}}$ $\mathrm{O}_{2} \mathrm{~N}_{2} \mathrm{BrClF}_{4} \mathrm{~S}[\mathrm{M}+\mathrm{H}]^{+}:$489.95003; found: 489.95001 .

$\mathrm{N}$-(2-((3-Bromobenzyl)sulfinyl)ethyl)-3-chloro-5-(trifluoromethyl) picolinamide (G5). Yield 50\%; white solid; mp 158-159 ${ }^{\circ} \mathrm{C} .{ }^{1} \mathrm{H}$ NMR (400 MHz, $\left.\mathrm{CDCl}_{3}\right) \delta 8.73(\mathrm{~d}, J=1.0 \mathrm{~Hz}, 1 \mathrm{H}$, pyridine-H), $8.41(\mathrm{t}, J=5.4 \mathrm{~Hz}, 1 \mathrm{H},-\mathrm{CO}-\mathrm{NH}-), 8.07$ (d, $J=1.3 \mathrm{~Hz}, 1 \mathrm{H}$, pyridine-H), 7.52-7.45 (m, 2H, Ar-H), 7.33-7.19 (m, 2H, Ar-H), 4.06-3.99 (m, 2H, $-\mathrm{CH}_{2}-$ ), 3.99-3.93 (m, 2H, $\left.-\mathrm{CH}_{2}-\right)$, 3.21-2.69 $\left(\mathrm{m}, 2 \mathrm{H},-\mathrm{CH}_{2}-\right) .{ }^{13} \mathrm{C} \mathrm{NMR}\left(100 \mathrm{MHz}, \mathrm{CDCl}_{3}\right) \delta 162.8,148.7,143.1$ (q, $J=3.8 \mathrm{~Hz}), 137.7$ (q, $J=3.5 \mathrm{~Hz}), 133.0,132.1,131.8,131.7$, 130.6, 129.4 (q, $J=34.1 \mathrm{~Hz}), 128.8,123.0,122.1$ (q, $J=273.4 \mathrm{~Hz})$, 57.7, 49.8, 34.4. $\left.{ }^{19} \mathrm{~F} \mathrm{NMR} \mathrm{(376} \mathrm{MHz,} \mathrm{CDCl}_{3}\right) \delta-62.56$. HRMS: calculated for $\mathrm{C}_{16} \mathrm{H}_{14} \mathrm{O}_{2} \mathrm{~N}_{2} \mathrm{BrClF}_{3} \mathrm{~S}[\mathrm{M}+\mathrm{H}]^{+}$: 468.95945; found: 468.95941.

3-Chloro-N-(2-((2,6-difluorobenzyl)sulfinyl)ethyl)-5(trifluoromethyl)picolinamide (G6). Yield 40\%; white solid; mp 
144-145 ${ }^{\circ} \mathrm{C} .{ }^{1} \mathrm{H}$ NMR $\left(400 \mathrm{MHz}, \mathrm{CDCl}_{3}\right) \delta 8.73(\mathrm{~d}, J=1.1 \mathrm{~Hz}, 1 \mathrm{H}$, pyridine-H), $8.43(\mathrm{t}, J=5.3 \mathrm{~Hz}, 1 \mathrm{H},-\mathrm{CO}-\mathrm{NH}-), 8.06(\mathrm{~d}, J=$ $1.3 \mathrm{~Hz}, 1 \mathrm{H}$, pyridine-H), 7.33 (tt, $J=8.4,6.5 \mathrm{~Hz}, 1 \mathrm{H}, \mathrm{Ar}-\mathrm{H}), 7.04-$ $6.91(\mathrm{~m}, 2 \mathrm{H}, \mathrm{Ar}-\mathrm{H}), 4.30-4.15\left(\mathrm{~m}, 2 \mathrm{H},-\mathrm{CH}_{2}-\right), 4.01$ (ddd, $J=8.4$, 5.3, $\left.1.6 \mathrm{~Hz}, 2 \mathrm{H},-\mathrm{CH}_{2}-\right)$, 3.20-2.86 (m, 2H, $\left.-\mathrm{CH}_{2}-\right) .{ }^{13} \mathrm{C}$ NMR (100 $\left.\mathrm{MHz}, \mathrm{CDCl}_{3}\right) \delta 161.5(\mathrm{~d}, J=250.7 \mathrm{~Hz}), 161.5(\mathrm{~d}, J=250.7 \mathrm{~Hz})$, $148.9,143.1(\mathrm{q}, J=3.9 \mathrm{~Hz}), 137.5(\mathrm{q}, J=3.6 \mathrm{~Hz}), 132.0,130.8(\mathrm{t}, J$ $=10.2 \mathrm{~Hz}), 129.3(\mathrm{q}, J=34.0 \mathrm{~Hz}), 122.1(\mathrm{q}, J=273.5 \mathrm{~Hz}), 111.8$ $(\mathrm{q}, J=25.3 \mathrm{~Hz}), 106.3(\mathrm{t}, J=19.4 \mathrm{~Hz}), 50.2,45.8,34.4 .{ }^{19} \mathrm{~F} \mathrm{NMR}$ $\left(376 \mathrm{MHz}, \mathrm{CDCl}_{3}\right) \delta-62.57,-112.09$. HRMS: calculated for $\mathrm{C}_{16} \mathrm{H}_{13} \mathrm{O}_{2} \mathrm{~N}_{2} \mathrm{ClF}_{5} \mathrm{~S}[\mathrm{M}+\mathrm{H}]^{+}$: 427.03009; found: 427.03006 .

3-Chloro-N-(2-((2-methylbenzyl)sulfinyl)ethyl)-5-

(trifluoromethyl)picolinamide (G7). Yield 52\%; white solid; mp 136-137 ${ }^{\circ} \mathrm{C} .{ }^{1} \mathrm{H}$ NMR $\left(400 \mathrm{MHz}, \mathrm{CDCl}_{3}\right) \delta 8.72(\mathrm{~d}, J=0.9 \mathrm{~Hz}, 1 \mathrm{H}$, pyridine-H), $8.45(\mathrm{t}, J=5.1 \mathrm{~Hz}, 1 \mathrm{H},-\mathrm{CO}-\mathrm{NH}-), 8.06(\mathrm{~d}, J=$ $1.3 \mathrm{~Hz}, 1 \mathrm{H}$, pyridine-H), 7.26-7.17 (m, 4H, Ar-H), 4.15 (dd, $J=$ 52.1, $\left.12.9 \mathrm{~Hz}, 2 \mathrm{H},-\mathrm{CH}_{2}-\right)$, 4.05-3.91 (m, 2H, $-\mathrm{CH}_{2}-$ ), 3.13-2.87 $\left(\mathrm{m}, 2 \mathrm{H},-\mathrm{CH}_{2}-\right), 2.41\left(\mathrm{~s}, 3 \mathrm{H},-\mathrm{CH}_{3}\right) .{ }^{13} \mathrm{C} \mathrm{NMR}\left(100 \mathrm{MHz}, \mathrm{CDCl}_{3}\right.$ ) $\delta 162.7,149.0,143.1(\mathrm{q}, J=3.8 \mathrm{~Hz}), 137.5(\mathrm{q}, J=7.2 \mathrm{~Hz}), 137.4$, 132.0, 131.1, 131.0, 129.3 (q, $J=34.0 \mathrm{~Hz}$ ), 128.9, 128.0, 126.7, $122.1(\mathrm{q}, J=273.5 \mathrm{~Hz}), 57.2,49.6,34.5,19.9 .{ }^{19} \mathrm{~F} \mathrm{NMR}(376 \mathrm{MHz}$, $\left.\mathrm{CDCl}_{3}\right) \delta-62.56$. HRMS: calculated for $\mathrm{C}_{17} \mathrm{H}_{17} \mathrm{O}_{2} \mathrm{~N}_{2} \mathrm{ClF}_{3} \mathrm{~S}[\mathrm{M}+$ $\mathrm{H}]^{+}$: 405.06459; found: 495.06454.

3-Chloro-5-(trifluoromethyl)-N-(2-((2-(trifluoromethyl)benzyl) sulfinyl)ethyl)picolinamide (G8). Yield 35\%; white solid; mp 131$132{ }^{\circ} \mathrm{C} .{ }^{1} \mathrm{H}$ NMR $\left(400 \mathrm{MHz}, \mathrm{CDCl}_{3}\right) \delta 8.73(\mathrm{~d}, J=1.0 \mathrm{~Hz}, 1 \mathrm{H}$, pyridine-H), $8.43(\mathrm{t}, J=5.2 \mathrm{~Hz}, 1 \mathrm{H},-\mathrm{CO}-\mathrm{NH}-), 8.07$ (d, $J=$ $1.3 \mathrm{~Hz}, 1 \mathrm{H}$, pyridine-H), 7.72 (d, $J=7.8 \mathrm{~Hz}, 1 \mathrm{H}, \mathrm{Ar}-\mathrm{H}), 7.61-7.54$ $(\mathrm{m}, 2 \mathrm{H}, \mathrm{Ar}-\mathrm{H}), 7.49(\mathrm{td}, J=8.2,4.7 \mathrm{~Hz}, 1 \mathrm{H}, \mathrm{Ar}-\mathrm{H}), 4.29-4.12(\mathrm{~m}$, $\left.2 \mathrm{H},-\mathrm{CH}_{2}-\right)$, 4.10-3.94 (m, 2H, $\left.-\mathrm{CH}_{2}^{-}\right)$, 3.21-2.93 (m, $2 \mathrm{H},-\mathrm{CH}_{2}-$ ). ${ }^{13} \mathrm{C} \mathrm{NMR}\left(100 \mathrm{MHz}, \mathrm{CDCl}_{3}\right) \delta 162.7,148.8,143.1$ (q, $J=3.8$ $\mathrm{Hz}), 137.6$ (q, $J=3.6 \mathrm{~Hz}), 132.9,132.3,132.1,129.3$ (q, $J=34.1$ $\mathrm{Hz}), 129.1$ (q, $J=30.1 \mathrm{~Hz}), 128.8,128.8,126.7$ (q, $J=5.5 \mathrm{~Hz}$ ), 124.1 (q, $J=273.9 \mathrm{~Hz}), 122.1$ (q, $J=273.5 \mathrm{~Hz}$ ), 56.2, 50.7, 34.5. ${ }^{19} \mathrm{~F} \mathrm{NMR}\left(376 \mathrm{MHz}, \mathrm{CDCl}_{3}\right) \delta-58.50,-62.58$. HRMS: calculated for $\mathrm{C}_{17} \mathrm{H}_{14} \mathrm{O}_{2} \mathrm{~N}_{2} \mathrm{ClF}_{6} \mathrm{~S}[\mathrm{M}+\mathrm{H}]^{+}$: 459.03632; found: 459.03586 .

3-Chloro-N-(2-((2-chlorobenzyl)sulfinyl)ethyl)-5-

(trifluoromethyl)picolinamide (G9). Yield 45\%; faint yellow solid; mp 127-128 ${ }^{\circ} \mathrm{C} .{ }^{1} \mathrm{H}$ NMR $\left(400 \mathrm{MHz}, \mathrm{CDCl}_{3}\right) \delta 8.73(\mathrm{~d}, J=1.1 \mathrm{~Hz}$, $1 \mathrm{H}$, pyridine-H), $8.42(\mathrm{t}, J=5.2 \mathrm{~Hz}, 1 \mathrm{H},-\mathrm{CO}-\mathrm{NH}-), 8.06(\mathrm{~d}, J=$ $1.3 \mathrm{~Hz}, 1 \mathrm{H}$, pyridine-H), 7.46-7.38 (m, 2H, Ar-H), 7.34-7.28 (m, $2 \mathrm{H}, \mathrm{Ar}-\mathrm{H}), 4.26\left(\mathrm{dd}, J=29.2,13.0 \mathrm{~Hz}, 2 \mathrm{H},-\mathrm{CH}_{2}-\right), 4.08-3.92(\mathrm{~m}$, $\left.2 \mathrm{H},-\mathrm{CH}_{2}-\right)$, 3.20-2.85 (m, 2H, $\left.-\mathrm{CH}_{2}-\right) .{ }^{13} \mathrm{C}$ NMR $(100 \mathrm{MHz}$, $\left.\mathrm{CDCl}_{3}\right) \delta 162.7,148.9,143.1(\mathrm{q}, J=3.9 \mathrm{~Hz}), 137.6(\mathrm{q}, J=3.6 \mathrm{~Hz})$, 134.6, 132.5, 132.1, 130.1, 130.0, 129.3 (q, $J=34.0 \mathrm{~Hz}$ ), 127.8, 127.4, 122.1 (q, $J=273.5 \mathrm{~Hz}), 56.1,49.8,34.5 .{ }^{19} \mathrm{~F}$ NMR (376 $\left.\mathrm{MHz}, \mathrm{CDCl}_{3}\right) \delta-62.55$. HRMS: calculated for $\mathrm{C}_{15} \mathrm{H}_{14} \mathrm{O}_{3} \mathrm{~N}_{2} \mathrm{Cl}_{2} \mathrm{~F}_{3} \mathrm{~S}$ $[\mathrm{M}+\mathrm{H}]^{+}$: 441.00488; found: 441.00427.

$\mathrm{N}$-(2-((4-(tert-Butyl)benzyl)sulfinyl)ethyl)-3-chloro-5-

(trifluoromethyl)picolinamide (G10). Yield 55\%; faint creamy yellow solid; mp 131-133 ${ }^{\circ} \mathrm{C} .{ }^{1} \mathrm{H}$ NMR (400 MHz, $\left.\mathrm{CDCl}_{3}\right) \delta 8.73$ (d, $J=0.9 \mathrm{~Hz}, 1 \mathrm{H}$, pyridine-H), $8.45(\mathrm{t}, J=5.4 \mathrm{~Hz}, 1 \mathrm{H},-\mathrm{CO}-\mathrm{NH}-$ ), $8.06(\mathrm{~d}, J=1.2 \mathrm{~Hz}, 1 \mathrm{H}$, pyridine- $\mathrm{H}), 7.40(\mathrm{~d}, J=8.2 \mathrm{~Hz}, 2 \mathrm{H}, \mathrm{Ar}-$ $\mathrm{H}), 7.23(\mathrm{~d}, J=8.2 \mathrm{~Hz}, 2 \mathrm{H}, \mathrm{Ar}-\mathrm{H}), 4.05\left(\mathrm{q}, J=13.0 \mathrm{~Hz}, 2 \mathrm{H},-\mathrm{CH}_{2}-\right.$ ), 4.00-3.93 (m, 2H, $\left.-\mathrm{CH}_{2}-\right)$, 3.09-2.78 (m, 2H, $\left.-\mathrm{CH}_{2}-\right), 1.31$ (s, 9H, $\left.-\mathrm{C}\left(\mathrm{CH}_{3}\right)_{3}\right) .{ }^{13} \mathrm{C} \mathrm{NMR}\left(100 \mathrm{MHz}, \mathrm{CDCl}_{3}\right) \delta 162.8,151.7,149.0$, $143.1(\mathrm{q}, J=3.8 \mathrm{~Hz}), 137.6(\mathrm{q}, J=3.6 \mathrm{~Hz}), 132.0,129.8,129.3(\mathrm{~d}, J$
$=34.0 \mathrm{~Hz}$ ), 126.1, 126.1, $122.1(\mathrm{q}, J=273.4 \mathrm{~Hz}), 58.1$, 49.2, 34.7, 34.5, 31.3. ${ }^{19} \mathrm{~F}$ NMR $\left(376 \mathrm{MHz}, \mathrm{CDCl}_{3}\right) \delta-62.56$. HRMS: calculated for $\mathrm{C}_{20} \mathrm{H}_{23} \mathrm{O}_{2} \mathrm{~N}_{2} \mathrm{ClF}_{3} \mathrm{~S}[\mathrm{M}+\mathrm{H}]^{+}$: 447.1154; found: 477.11038.

3-Chloro-N-(2-(((6-chloropyridin-3-yl)methyl)sulfinyl)ethyl)-5(trifluoromethyl)picolinamide (G11). Yield 72\%; soil yellow solid; mp 136-137 ${ }^{\circ} \mathrm{C} .{ }^{1} \mathrm{H}$ NMR $\left(400 \mathrm{MHz}, \mathrm{CDCl}_{3}\right) \delta 8.73(\mathrm{~d}, J=1.1 \mathrm{~Hz}$, $1 \mathrm{H}$, pyridine- $\mathrm{H}), 8.38(\mathrm{t}, J=5.2 \mathrm{~Hz}, 1 \mathrm{H},-\mathrm{CO}-\mathrm{NH}-), 8.35(\mathrm{~d}, J=$ $2.3 \mathrm{~Hz}, 1 \mathrm{H}$, pyridine- $\mathrm{H}), 8.08$ (d, $J=1.3 \mathrm{~Hz}, 1 \mathrm{H}$, pyridine- $\mathrm{H}), 7.68$ (dd, $J=8.2,2.4 \mathrm{~Hz}, 1 \mathrm{H}$, pyridine-H), 7.37 (d, $J=8.2 \mathrm{~Hz}, 1 \mathrm{H}$, pyridine-H), 4.16-3.86 (m, $\left.4 \mathrm{H},-\mathrm{CH}_{2}-\right)$, 3.25-2.76 (m, $2 \mathrm{H},-\mathrm{CH}_{2}-$ ). ${ }^{13} \mathrm{C} \mathrm{NMR}\left(100 \mathrm{MHz}, \mathrm{CDCl}_{3}\right) \delta 162.9,151.9,150.7,148.4,143.0$ $(\mathrm{q}, J=3.8 \mathrm{~Hz}), 140.4,137.8(\mathrm{q}, J=3.6 \mathrm{~Hz}), 132.2,129.5(\mathrm{q}, J=$ $34.0 \mathrm{~Hz}$ ), 124.7, 124.5, 122.1 (q, $J=273.5 \mathrm{~Hz}$ ), 53.9, 50.3, 34.3. ${ }^{19} \mathrm{~F} \mathrm{NMR}\left(376 \mathrm{MHz}, \mathrm{CDCl}_{3}\right) \delta-62.56$. HRMS: calculated for $\mathrm{C}_{15} \mathrm{H}_{13} \mathrm{O}_{2} \mathrm{~N}_{3} \mathrm{Cl}_{2} \mathrm{~F}_{3} \mathrm{~S}[\mathrm{M}+\mathrm{H}]^{+}: 426.00521$; found: 426.00473 .

3-Chloro-N-(2-((4-cyanobenzyl)sulfinyl)ethyl)-5-(trifluoromethyl) picolinamide (G12). Yield 39\%; pale yellow solid; mp $172-173{ }^{\circ} \mathrm{C}$. ${ }^{1} \mathrm{H}$ NMR $\left(400 \mathrm{MHz}, \mathrm{CDCl}_{3}\right) \delta 8.72(\mathrm{~s}, 1 \mathrm{H}$, pyridine-H), $8.36(\mathrm{t}, J=$ $5.3 \mathrm{~Hz}, 1 \mathrm{H},-\mathrm{CO}-\mathrm{NH}-), 8.08(\mathrm{~s}, 1 \mathrm{H}$, pyridine-H), $7.69(\mathrm{~d}, J=$ $7.7 \mathrm{~Hz}, 2 \mathrm{H}, \mathrm{Ar}-\mathrm{H}), 7.45$ (d, $J=7.9 \mathrm{~Hz}, 2 \mathrm{H}, \mathrm{Ar}-\mathrm{H}), 4.09$ (dd, $J=$ $\left.53.4,13.0 \mathrm{~Hz}, 2 \mathrm{H},-\mathrm{CH}_{2}-\right)$, 4.00-3.83 (m, 2H, $\left.-\mathrm{CH}_{2}-\right)$, 3.31-2.77 $\left(\mathrm{m}, 2 \mathrm{H},-\mathrm{CH}_{2}-\right) .{ }^{13} \mathrm{C} \mathrm{NMR}\left(100 \mathrm{MHz}, \mathrm{CDCl}_{3}\right) \delta 162.9,148.5,143.0$ $(\mathrm{q}, J=3.8 \mathrm{~Hz}), 137.8(\mathrm{q}, J=3.6 \mathrm{~Hz}), 135.0,132.7,132.2,131.0$, $129.5(\mathrm{q}, J=34.1 \mathrm{~Hz}), 122.1$ (q, $J=273.5 \mathrm{~Hz}), 118.3,112.6,57.6$, 50.3, 34.3. ${ }^{19} \mathrm{~F}$ NMR $\left(376 \mathrm{MHz}, \mathrm{CDCl}_{3}\right) \delta-62.56$. HRMS: calculated for $\mathrm{C}_{17} \mathrm{H}_{11} \mathrm{O}_{2} \mathrm{~N}_{3} \mathrm{Cl}_{2} \mathrm{~F}_{3} \mathrm{~S}[\mathrm{M}+\mathrm{H}]^{+}$: 432.03910; found: 432.03787.

3-Chloro-N-(2-((3,5-difluorobenzyl)sulfinyl)ethyl)-5-

(trifluoromethyl)picolinamide (G13). Yield 34\%; soil white solid; mp 154-155 ${ }^{\circ} \mathrm{C} .{ }^{1} \mathrm{H}$ NMR $\left(400 \mathrm{MHz}, \mathrm{CDCl}_{3}\right) \delta 8.73(\mathrm{~d}, J=1.1 \mathrm{~Hz}$, $1 \mathrm{H}$, pyridine- $\mathrm{H}), 8.40(\mathrm{t}, J=5.5 \mathrm{~Hz}, 1 \mathrm{H},-\mathrm{CO}-\mathrm{NH}-), 8.08(\mathrm{~d}, J=$ $1.4 \mathrm{~Hz}, 1 \mathrm{H}$, pyridine- $\mathrm{H}), 6.93-6.85(\mathrm{~m}, 2 \mathrm{H}, \mathrm{Ar}-\mathrm{H}), 6.82(\mathrm{ddt}, J=$ 11.2, 8.9, $2.5 \mathrm{~Hz}, 1 \mathrm{H}, \mathrm{Ar}-\mathrm{H}), 4.11-3.87$ (m, 4H, $\left.-\mathrm{CH}_{2}-\right)$, 3.23-2.80 $\left(\mathrm{m}, 2 \mathrm{H},-\mathrm{CH}_{2}-\right) .{ }^{13} \mathrm{C} \mathrm{NMR}\left(100 \mathrm{MHz}, \mathrm{CDCl}_{3}\right) \delta 163.2(\mathrm{~d}, J=250.3$ $\mathrm{Hz}), 163.0$ (d, $J=250.3 \mathrm{~Hz}), 162.9,148.6,143.1$ (q, $J=3.9 \mathrm{~Hz}$ ), $137.7(\mathrm{q}, J=3.5 \mathrm{~Hz}), 133.2(\mathrm{t}, J=9.6 \mathrm{~Hz}), 132.2,129.5(\mathrm{q}, J=34.1$ $\mathrm{Hz}), 122.1$ (q, $J=273.4 \mathrm{~Hz}), 113.2(\mathrm{dd}, J=11.4 \mathrm{~Hz}, 25.9 \mathrm{~Hz})$, $104.3(\mathrm{t}, J=25.1 \mathrm{~Hz}), 57.5,50.2,34.3 .{ }^{19} \mathrm{~F} \mathrm{NMR}\left(376 \mathrm{MHz}, \mathrm{CDCl}_{3}\right)$ $\delta-62.58,-108.29$. HRMS: calculated for $\mathrm{C}_{16} \mathrm{H}_{13} \mathrm{O}_{2} \mathrm{~N}_{2} \mathrm{ClF}_{5} \mathrm{~S}[\mathrm{M}+$ $\mathrm{H}]^{+}$: 427.03009; found: 427.02844 .

3-Chloro-N-(2-(((3-methyl-4-(2,2,2-trifluoroethoxy)pyridin-2-yl) methyl)sulfinyl)ethyl)-5-(trifluoromethyl)picolinamide (G14). Yield 41\%; white solid; mp 126-127 ${ }^{\circ} \mathrm{C} .{ }^{1} \mathrm{H}$ NMR (400 MHz, $\mathrm{CDCl}_{3}$ ) $\delta 8.72(\mathrm{~d}, J=1.0 \mathrm{~Hz}, 1 \mathrm{H}$, pyridine $-\mathrm{H}), 8.62(\mathrm{t}, J=5.1 \mathrm{~Hz}, 1 \mathrm{H}$, -CO-NH-), 8.35 (d, $J=5.6 \mathrm{~Hz}, 1 \mathrm{H}$, pyridine-H), $8.06(\mathrm{~d}, J=$ $1.4 \mathrm{~Hz}, 1 \mathrm{H}$, pyridine- $\mathrm{H}), 6.70(\mathrm{~d}, J=5.6 \mathrm{~Hz}, 1 \mathrm{H}$, pyridine- $\mathrm{H})$, 4.51-4.25 (m, 4H, $-\mathrm{CH}_{2}-$ ), 4.02 (dd, $J=11.8,5.9 \mathrm{~Hz}, 2 \mathrm{H}$, $\left.-\mathrm{CH}_{2}-\right)$, 3.50-2.79 (m, 2H, $\left.-\mathrm{CH}_{2}-\right), 2.32\left(\mathrm{~s}, 3 \mathrm{H},-\mathrm{CH}_{3}\right) .{ }^{13} \mathrm{C} \mathrm{NMR}$ $\left(100 \mathrm{MHz}, \mathrm{CDCl}_{3}\right) \delta 162.7,161.9,150.9,149.2,148.4,143.0(\mathrm{q}, J$ $=3.8 \mathrm{~Hz}), 137.5(\mathrm{q}, J=3.5 \mathrm{~Hz}), 132.0,129.2(\mathrm{q}, J=34.0 \mathrm{~Hz})$, 122.8 (q, $J=277.7 \mathrm{~Hz}), 122.141$ (q, $J=273.5 \mathrm{~Hz}), 123.4,105.9$, $65.4(\mathrm{q}, J=36.5 \mathrm{~Hz}), 57.5,50.2,34.3,11.2 .{ }^{19} \mathrm{~F} \mathrm{NMR}(376 \mathrm{MHz}$, $\left.\mathrm{CDCl}_{3}\right) \delta-62.57,-73.78$. HRMS: calculated for $\mathrm{C}_{18} \mathrm{H}_{17} \mathrm{O}_{3} \mathrm{~N}_{3}$ $\mathrm{ClF}_{6} \mathrm{~S}[\mathrm{M}+\mathrm{H}]^{+}$: 504.05779; found: 504.05603.

3-Chloro-N-(2-((3,4,4-trifluorobut-3-en-1-yl)sulfinyl)ethyl)-5(trifluoromethyl)picolinamide (G15). Yield 30\%; pale yellow solid; 
mp 100-101 ${ }^{\circ} \mathrm{C} .{ }^{1} \mathrm{H}$ NMR (400 $\left.\mathrm{MHz}, \mathrm{CDCl}_{3}\right) \delta 8.74(\mathrm{~s}, 1 \mathrm{H}$, pyridine-H), 8.45 (s, 1H, -CO-NH-), 8.08 (d, $J=1.2 \mathrm{~Hz}, 1 \mathrm{H}$, pyridine- $\mathrm{H}$ ), 4.01 (dd, $\left.J=11.8,5.9 \mathrm{~Hz}, 2 \mathrm{H},-\mathrm{CH}_{2}-\right)$, 3.31-2.94 (m, $2 \mathrm{H},-\mathrm{CH}_{2}-$ ), 2.86 (ddd, $J=12.6,10.7,8.4 \mathrm{~Hz}, 2 \mathrm{H},-\mathrm{CH}_{2}-$ ). ${ }^{13} \mathrm{C}$ NMR (100 MHz, $\mathrm{CDCl}_{3}$ ) $\delta$ 162.8, 153.1 (ddd, $J=288.2$, 275.3, $45.7 \mathrm{~Hz}), 148.6,143.1$ (q, $J=3.8 \mathrm{~Hz}), 137.7$ (q, $J=3.5 \mathrm{~Hz}), 132.2$, $129.5(\mathrm{q}, J=34.4 \mathrm{~Hz}), 126.3(\mathrm{ddd}, J=234.8,53.5,17.5 \mathrm{~Hz}), 122.1$ (q, $J=273.5 \mathrm{~Hz}), 51.2,48.1,34.5,19.8(\mathrm{dd}, J=22.2,2.3 \mathrm{~Hz}) \cdot{ }^{19} \mathrm{~F}$ NMR $\left(376 \mathrm{MHz}, \mathrm{CDCl}_{3}\right) \delta-62.59,-102.12(\mathrm{dd}, J=82.1,33.0$ $\mathrm{Hz}),-121.38$ (ddd, $J=115.7,82.5,4.4 \mathrm{~Hz}$ ), -175.45 (dd, $J=$ 114.8, $33.0 \mathrm{~Hz}$ ). HRMS: calculated for $\mathrm{C}_{13} \mathrm{H}_{11} \mathrm{O}_{2} \mathrm{~N}_{3} \mathrm{Cl}_{2} \mathrm{~F}_{3} \mathrm{~S}_{2}[\mathrm{M}+$ $\mathrm{H}]^{+}$: 431.96163; found: 431.96161 .

3-Chloro-N-(2-((2,5-difluorobenzyl)sulfinyl)ethyl)-5-

(trifluoromethyl)picolinamide (G16). Yield 30\%; white solid; mp 123-125 ${ }^{\circ} \mathrm{C} .{ }^{1} \mathrm{H}$ NMR $\left(400 \mathrm{MHz}, \mathrm{CDCl}_{3}\right) \delta 8.73(\mathrm{~d}, J=0.9 \mathrm{~Hz}, 1 \mathrm{H})$, $8.40(\mathrm{t}, J=4.8 \mathrm{~Hz}, 1 \mathrm{H}), 8.07(\mathrm{~d}, J=1.4 \mathrm{~Hz}, 1 \mathrm{H}), 7.18-6.93(\mathrm{~m}$, $2 \mathrm{H}), 4.08(\mathrm{dd}, J=36.3,13.2 \mathrm{~Hz}, 2 \mathrm{H}), 3.98(\mathrm{dd}, J=12.0,6.1 \mathrm{~Hz}$, 2H), 3.17-2.82 (m, 2H). ${ }^{13} \mathrm{C}$ NMR (100 MHz, $\left.\mathrm{CDCl}_{3}\right) \delta 162.8$, $158.5(\mathrm{dd}, J=244.3,2.3 \mathrm{~Hz}), 157.0$ (dd, $J=243.6,2.6 \mathrm{~Hz}), 148.7$, $143.0(\mathrm{q}, J=3.8 \mathrm{~Hz}), 137.6(\mathrm{q}, J=3.5 \mathrm{~Hz}), 132.1,129.4(\mathrm{q}, J=$ $34.1 \mathrm{~Hz}), 122.1(\mathrm{q}, J=273.4 \mathrm{~Hz}), 118.9(\mathrm{~d}, J=3.6 \mathrm{~Hz}), 118.6(\mathrm{~d}, J$ $=3.6 \mathrm{~Hz}), 118.4(\mathrm{dd}, J=17.9,8.3 \mathrm{~Hz}), 117.0(\mathrm{td}, J=24.4,8.6 \mathrm{~Hz})$, 50.8, 50.0, 34.4. ${ }^{19} \mathrm{~F}$ NMR $\left(376 \mathrm{MHz}, \mathrm{CDCl}_{3}\right) \delta-62.57,-117.43$ (d, $J=17.9 \mathrm{~Hz}),-122.28$ (d, $J=17.8 \mathrm{~Hz})$. HRMS: calculated for $\mathrm{C}_{16} \mathrm{H}_{13} \mathrm{O}_{2} \mathrm{~N}_{2} \mathrm{ClF}_{5} \mathrm{~S}[\mathrm{M}+\mathrm{H}]^{+}$: 427.03009; found: 427.02939 .

4.2.5 In vitro antibacterial activities against $X o o$ and $R$. solanacearum test. According to the reported procedure, ${ }^{49}$ in vitro antibacterial activities of title compounds against Xoo and $R$. solanacearum were carried out. Firstly, $5 \mathrm{~mL}$ nutrient broths (NB) containing synthesized compounds solution $\left(100 \mathrm{mg} \mathrm{L}^{-1}\right.$ or $50 \mathrm{mg} \mathrm{L}^{-1}$ ) were prepared. NB containing commercialized thiodiazole copper (TC) or bismerthiazol (BT) solution (100 $\mathrm{mg} \mathrm{L}^{-1}$ or $50 \mathrm{mg} \mathrm{L}^{-1}$ ) were also prepared as the positive controls, and NB containing sterile distilled water was used as negative control. Following this, $40 \mu \mathrm{L}$ Xoo or $R$. solanacearum, was added to each NB medium. The inoculated samples above were cultured together in a shaker $\left(180 \mathrm{rpm}, 28{ }^{\circ} \mathrm{C}\right)$ for about 24-48 h, until negative control had grown to logarithmic phase. Using a microplate reader, the turbidity of each inoculated samples was measured under $595 \mathrm{~nm}$, which was corrected by the equation of $T=\mathrm{OD}_{\text {bacterial }}-\mathrm{OD}_{\mathrm{no}}$ bacterial. Then the final activities against Xoo or $R$. solanacearum, was calculated by the following equation:

$$
\text { Activity: } I=(C-T) / C \times 100 \% \text {, }
$$

$C$ represents the turbidity of the NB without treatment solution (negative control), and $T$ represents the corrected turbidity. The antibacterial activities of synthesized compounds against Xoo or $R$. solanacearum, were tested for three times.

4.2.6 Insecticidal activity test against $P$. xylostella. The insecticidal activity was tested at $25 \pm 1{ }^{\circ} \mathrm{C}$ according to statistical requirements. Mortalities were calculated and based on a percentage scale using Abbott's formula. ${ }^{50}$ Using previously procedures, ${ }^{51}$ fresh cabbage discs (diameter $9 \mathrm{~cm}$ ) were dipped into the synthesized solutions $\left(500 \mathrm{mg} \mathrm{L}^{-1}\right)$ and placed in a Petri dish with two moist filter papers. The chlorpyrifos and avermectin were used as positive control and water without any compounds was used as negative control at the same condition. Fifteen larvae of second instar $P$. xylostella were carefully transferred to the Petri dish and cultivated for $72 \mathrm{~h}$. Three replicates were measured for each treatment.

\section{Conflicts of interest}

There are no conflicts to declare.

\section{Acknowledgements}

This work was supported by the National Natural Science Foundation of China (No. 21762012), and Program of Introducing Talents to Chinese Universities (111 Program, D20023), and the S\&T Planning Project of Guizhou Province (No. [2017] 1402, [2017]5788).

\section{Notes and references}

1 F. P. Carvalho, Food Energy Secur., 2017, 6, 48.

2 R. N. Strange and P. R. Scott, Annu. Rev. Phytopathol., 2005, 43, 83.

3 S. H. Ou, Rice Diseases, Commonwealth Agricultural Bureau, 1985.

4 N. Huang, E. R. Angeles, J. Domingo, G. Magpantay, S. Singh, G. Zhang, N. Kumaravadivel, J. Bennett and G. S. Khush, Theor. Appl. Genet., 1997, 95, 313.

5 A. C. Hayward, Annu. Rev. Phytopathol., 1991, 29, 65.

6 G. Kemmitt, T. C. Sparks, J. E. Hunter, B. A. Lorsbach, G. Hanger, R. E. Gast and R. J. Bryant, J. Agric. Food. Chem., 2018, 66, 10337.

7 T. H. Kim, J. W. Jeong, J. H. Song, K. R. Lee, S. Ahn, S. H. Ahn, S. S. Kim and T. S. Koo, Arch. Pharmacal Res., 2015, 38, 2076.

8 M. I. Ansari, M. M. Khan, M. Saquib, S. Khatoon and M. K. Hussain, Future Med. Chem., 2018, 10, 1241.

9 J. Zhao and X. Jiang, Chin. Chem. Lett., 2018, 29, 1079.

10 Q. Jing, X. Hu, M. Yanzi, J. H. Mu, W. W. Liu, F. X. Xu, Z. L. Li, J. Bai, H. M. Hua and D. H. Li, Mar. Drugs, 2019, 17, 384.

11 S. Pathania, R. K. Narang and R. K. Rawal, Eur. J. Med. Chem., 2019, 180, 486.

12 R. R. Singhaus, R. C. Bernotas, R. Steffan, E. Matelan, E. Quinet, P. Nambi, I. Feingold, C. Huselton, A. Wilhelmsson, A. Goos-Nilsson and J. Wrobel, Bioorg. Med. Chem. Lett., 2010, 20, 521.

13 B. Prasad, R. Adepu, S. Sandra, D. Rambabu, G. Krishna, R. Rama, C. Malla, G. S. Deora, P. Misra and M. Pal, Chem. Commun., 2012, 48, 10434.

14 A. Kallinen, R. Boyd, S. Lane, R. Bhalla, K. Mardon, D. H. R. Stimson, E. L. Werry, R. Fulton, M. Connor and M. Kassiou, Org. Biomol. Chem., 2019, 17, 5086.

15 F. Z. Karadayi, M. Yaman, M. M. Kisla, A. G. Keskus, O. Konu and Z. A. Alagoz, Bioorg. Chem., 2020, 100, 103929.

16 S. Mondal, K. Mahato, N. Arora, D. Kankane, U. P. Singh, S. Ali, A. H. Khan, S. S. Ghosh and A. T. Khan, Org. Biomol. Chem., 2020, 18, 4104. 
17 T. Wang, T. Peng, X. X. Wen, G. Wang, Y. B. Sun, S. C. Liu, S. G. Zhang and L. Wang, Molecules, 2019, 24, 4034.

18 G. L. Regina, M. C. Edler, A. Brancale, S. Kandil, A. Coluccia, F. Piscitelli, E. Hamel, G. D. Martino, R. Matesanz, J. F. Diaz, A. I. Scovassi, E. Prosperi, A. Lavecchia, E. Novellino, M. Artico and R. Silvestri, J. Med. Chem., 2007, 50, 2865.

19 R. Ragno, A. Coluccia, G. L. Regina, G. D. Martino, F. Piscitelli, A. Lavecchia, E. Novellino, A. Bergamini, C. Ciaprini, A. Sinistro, G. Maga, E. Crespan, M. Artico and R. Silvestri, J. Med. Chem., 2006, 49, 3172.

20 V. Famiglini, G. L. Regina, A. Coluccia, S. Pelliccia, A. Brancale, G. Maga, E. Crespan, R. Badia, E. RiveiraMunoz, J. A. Este, R. Ferretti, R. Cirilli, C. Zamperini, M. Botta, D. Schols, V. Limongelli, B. Agostino, E. Novellino and R. Silvestri, J. Med. Chem., 2014, 57, 9945. 21 D. Alia and K. F. Frank, Expert Opin. Drug Saf., 2009, 8, 119. 22 B. Shu, Q. Yu, D. X. Hu, T. Che, S. S. Zhang and D. Li, Bioorg. Med. Chem. Lett., 2020, 30, 126925.

23 K. L. Manasa, S. Pujitha, A. Sethi, M. Arifuddin, M. Alvala, A. Angeli and C. T. Supuran, Metabolites, 2020, 10, 136.

24 G. T. Gibney and J. S. Zager, J. Drug Metab. Toxicol., 2013, 9, 893.

25 P. Koelblinger, O. Thuerigen and R. Dummer, Curr. Opin. Oncol., 2018, 30, 125.

26 W. F. Richard, B. Christine, C. C. Chi, C. Stella, D. Denis, D. Daniel, E. Diane, Y. G. Jacques, G. Yves, G. Robert, M. G. Gillian, R. Denis, S. Chantal, Z. Y. Wang, E. Wong, D. Visco, L. J. Xu and R. N. Young, Bioorg. Med. Chem. Lett., 1998, 8, 2777.

27 P. Srinivas, P. Manojit and Y. K. Rao, Tetrahedron, 2003, 59, 7915.

28 W. M. Xu, S. Z. Li, M. He, S. Yang, X. Y. Li and P. Li, Bioorg. Med. Chem. Lett., 2013, 23, 5821.

29 P. Y. Wang, L. Zhou, J. Zhou, Z. B. Wu, W. Xue, B. A. Song and S. Yang, Bioorg. Med. Chem. Lett., 2016, 26, 1214.

30 Y. T. Zheng, T. T. Zhang, P. Y. Wang, Z. B. Wu, L. Zhou, I. Q. Ye, X. Zhou, M. He and S. Yang, Chin. Chem. Lett., 2017, 28, 253.

31 P. Li, J. L. Zhou, Y. Liu and X. Wang, Chem. Pap., 2020, DOI: 10.1007/s11696-020-01271-6.
32 I. Grib, M. Berredjem, K. O. Rachedi, S. E. Djouad, S. Bouacida, R. Bahadi, T. S. Ouk, M. Kadri, T. B. Hadda and B. Belhani, J. Mol. Struct., 2020, 1217, 128423.

33 M. Z. Zhang, N. Mulholland, D. Beattie, D. Irwin, Y. C. Gu, G. F. Yang and C. John, Eur. J. Med. Chem., 2013, 63, 22.

34 S. Y. Ke, W. Fang, W. B. Huang, Z. G. Zhang, L. Q. Shi, Z. Y. Wan, K. M. Wang, C. X. Cao and D. Y. Huang, Bioorg. Med. Chem. Lett., 2020, 30, 127245.

35 M. A. Gonzalez, D. B. Gorman, C. T. Hamilton and G. A. Roth, Org. Process Res. Dev., 2008, 12, 301.

36 J. M. Babcock, C. B. Gerwick, J. X. Huang, M. R. Loso, G. Nakamura, S. P. Nolting, R. B. Rogers, T. C. Sparks, J. Thomas, G. B. Watson and Y. Zhu, Pest Manage. Sci., 2011, 67, 328.

37 Z. B. Yang, P. Li, Y. J. He, J. Luo, J. Zhou, Y. H. Wu and L. T. Chen, Chem. Pap., 2020, 74, 1621.

38 S. Patai, Z. Rappoport and C. Stirling, The Chemistry of Sulphones and Sulphoxides, John Wiley \& Sons, Ltd, 2006.

39 A.-N. R. Alba, X. Companyó and R. Rios, Chem. Soc. Rev., 2010, 39, 2018.

40 M. Nielsen, C. B. Jacobsen, N. Holub, M. W. Paixão and K. A. Jørgensen, Angew. Chem., Int. Ed., 2010, 49, 2668.

41 T. Haga, Y. Tsujii, K. Hayashi, F. Kimura, N. Sakashita and K. Fujikawa, ACS Symp. Ser., 1991, 443, 107.

42 I. Katsuyama, Yuki Gosei Kagaku Kyokaishi, 2009, 67, 992.

43 B. Adam, J. F. Edmunds, D. E. Daniel, H. G. Roger, J. Olivier and S. Juergen, Pest Manage. Sci., 2018, 74, 1228.

44 F. Z. Xu, Y. Y. Wang, D. X. Luo, G. Yu, S. X. Guo, H. Fu, Y. H. Zhao and J. Wu, RSC Adv., 2018, 8, 6306.

45 F. Z. Xu, Y. Y. Wang, D. X. Luo, G. Yu, Y. k. Wu, A. L. Dai, Y. H. Zhao and J. Wu, ChemistrySelect, 2018, 3, 2795.

46 A. L. Dai, S. X. Guo, C. H. Li, R. F. Zhang and J. Wu, Mod. Agrochem., 2020, 19, 21.

47 P. Li, D. Y. Hu, D. D. Xie, J. X. Chen, L. H. Jin and B. A. Song, J. Agric. Food Chem., 2018, 66, 3093.

48 P. Li, P. Y. Tian, Y. Z. Chen, X. P. Song, W. Xue, L. H. Jin, D. Y. Hu and B. A. Song, Pest Manage. Sci., 2018, 74, 844.

49 P. Dalgaard, T. Ross, L. Kamperman, K. Neumeyer and T. A. McMeekin, Int. J. Food Microbiol., 1994, 23, 391.

50 W. S. Abbott, J. Am. Mosq. Control Assoc., 1987, 3, 302.

51 Q. Q. Zhao, Y. Q. Li, L. X. Xiong and Q. M. Wang, J. Agric. Food Chem., 2010, 58, 4992. 